Portland State University

PDXScholar

$1-1-2011$

\title{
Exploration of Weather Impacts on Freeway Traffic Operations and Safety Using High-Resolution Weather Data
}

Chengyu Dai

Portland State University

Follow this and additional works at: https://pdxscholar.library.pdx.edu/open_access_etds Let us know how access to this document benefits you.

Recommended Citation

Dai, Chengyu, "Exploration of Weather Impacts on Freeway Traffic Operations and Safety Using HighResolution Weather Data" (2011). Dissertations and Theses. Paper 255.

https://doi.org/10.15760/etd.255

This Thesis is brought to you for free and open access. It has been accepted for inclusion in Dissertations and Theses by an authorized administrator of PDXScholar. Please contact us if we can make this document more accessible: pdxscholar@pdx.edu. 
Exploration of Weather Impacts on Freeway Traffic Operations and Safety

Using High-Resolution Weather Data

\author{
by \\ Chengyu Dai
}

A thesis submitted in partial fulfillment of the requirements for the degree of

\author{
Master of Science \\ in \\ Civil and Environmental Engineering
}

Thesis Committee:

Christopher M. Monsere, Chair

Hamid Moradkhani

Kristin Tufte

Portland State University

(C)2012 


\begin{abstract}
Adverse weather is considered as one of the important factors contributing to injuries and severe crashes. During rainy conditions, it can reduce travel visibility, increase stopping distance, and create the opportunity hydroplaning. This study quantified the relative crash risk on Oregon 217 southbound direction under rainy conditions by using a match-paired approach, applied one-year traffic data, crash data and NEXRAD Level II radar weather data. There are 26 crashes occurred in match-paired weather conditions for Oregon 217 in year 2007. The results of this study indicate that a higher crash risk and a higher property-damage-only crash risk occurred during rainy days. The crash risk level varies by the location of the highway, at milepost 2.55 station SW Allen Blvd has the highest driving risks under rainy conditions.
\end{abstract}




\section{ACKNOWLEDGEMENTS}

Thanks to my advisor, Dr. Chris Monsere, provided invaluable feedback and support over my study and research in Portland State University, and many thanks to the other two members of my thesis committee, Dr. Hamid Moradkhani and Dr. Kristin Tufte.

This thesis also is dedicated to my lovely and supportive family, many thanks to my sister Chengxin Dai, my husband Charles Kuo, dad and mom. 


\section{Table of Contents}

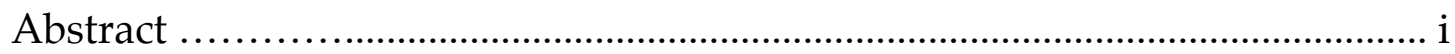

Acknowledgments ................................................................................. ii

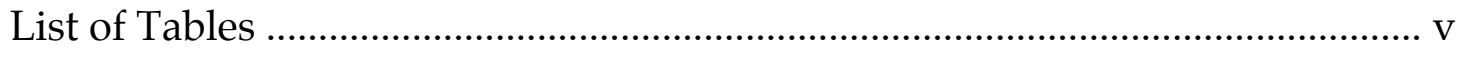

List of Figures ......................................................................................... vi

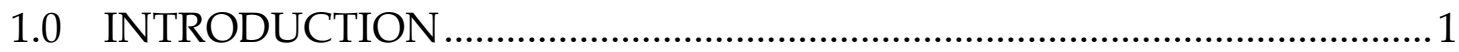

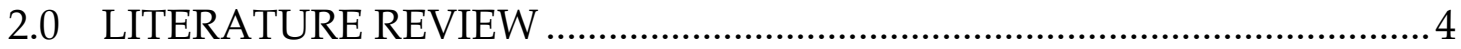

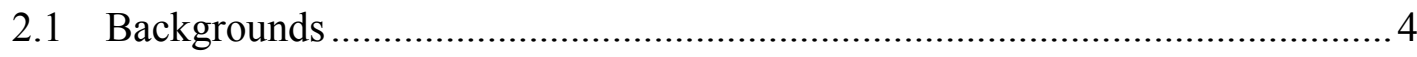

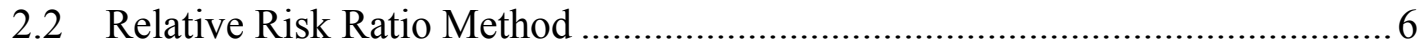

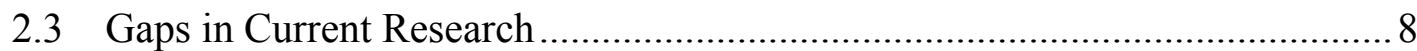

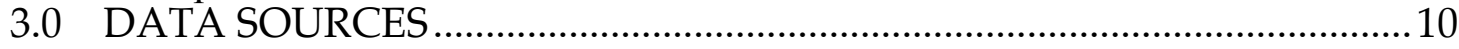

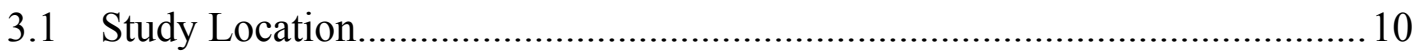

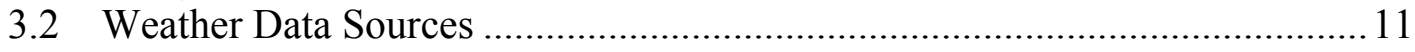

3.2.1 PORTAL Data Archive- Weather Satiation Data ................................... 11

3.2.2 Next Generation Weather Radar Doppler (NEXRAD) Data ................... 14

3.2.3 PORTAL VS. NEXRAD Weather Data................................................... 19

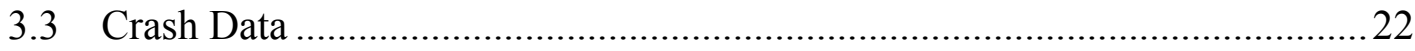

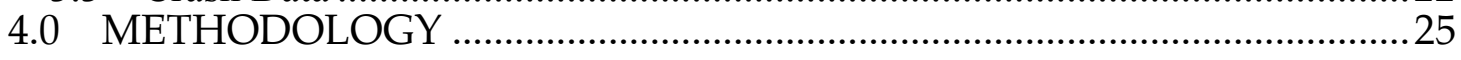

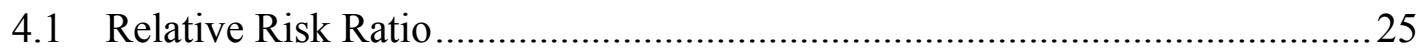

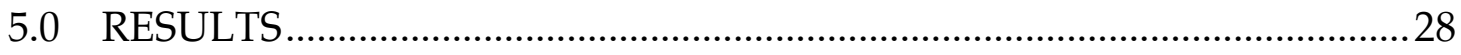

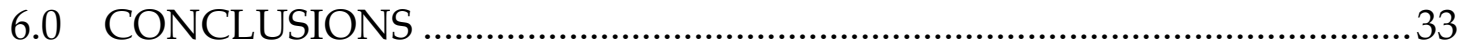

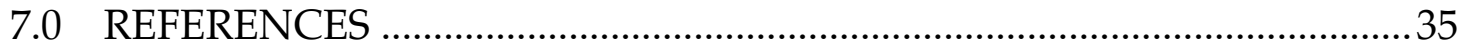




\section{APPENDIX}

APPENDIX A: Summary of studies ....................................... 38

APPENDIX B: NEXRAD Ten-minute Precipitation by Month .................. 39

APPENDIX C: NEXRAD Ten-minute Precipitation with Crashes ..............45

APPENDIX D: PORTAL Hourly Precipitation by Month .................... 51 
Table 1: Percentage of Injury and Fatal Collisions...........................................2

Table 2: Summary of NEXRAD radar and PORTAL weather data ................... 19

Table 3: Paired T-test Result for Different Milepost ............................................ 20

Table 4: Summary of OR-217 Crashes for Rainy Conditions, 2007 .................. 24

Table 5: Monthly Distribution of Crashes on OR-217 in Rainy Days, 2007 ...... 24

Table 6 : Criteria for Selecting Event and Control Periods ................................26

Table 7 : Result of Relative Crash Risk for Different Weather Data...................28

Table 8 : Relative Crash Risk Ratio by Mile Post ..............................................29

Table 9 : Severity Analysis with Match-paired by NEXRAD Radar Data........ 30

Table 10: Crash Occurrence with Traffic Volume (in vplph) ........................... 31

Table 11: Crash Occurrence with Traffic Speed (in mph) ................................. 32 
Figure 1: Risk Matrix: combination of probability and consequence ................5

Figure 2: Maps of Oregon 217 Soundbound Direction ..................................... 11

Figure 3: PORTAL Data Archive Contents .................................................. 12

Figure 4: Example of PORTAL Weather Data .................................................... 13

Figure 5 : National Doppler Radar Sites ........................................................ 14

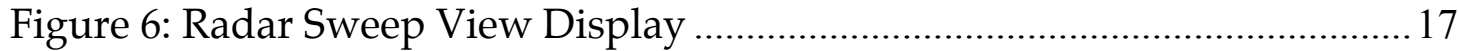

Figure 7: Converting into ArcGIS Map ............................................................ 18

Figure 8: PORTAL Weather Data and Radar Data at Milepost 0.76 in 2007.... 21

Figure 9: Weather Sample at Hillsboro Airport ................................................ 21

Figure 10: Summary of Types of Crash for Oregon 217...................................22

Figure 11: Seasonal Patterns of Crash for Oregon 217 in year 2007 ................. 23

Figure 12: Number of Crashes on OR-217 by Milepost Rainy Conditions ....... 30 


\subsection{INTRODUCTION}

Adverse weather conditions are often cited as an important factor contributing to injuries and severe crashes on roadways (Sun, 2010). In addition, adverse weather is the second largest cause of non-recurring congestion, accounting for about $25 \%$ of travel delay (Alfelor, 2006). Based on historical collision records from different countries, rain has the most significant weather impact for driving conditions on roadways. Rainy conditions reduce travel visibility, increase stopping distance, and create the opportunity for hydroplaning. Table 1 indicates the percentage of injury and fatal collisions during selected weather conditions in three different countries (United States, Great Britain, and Canada). As shown, the rain condition accounts for the highest percentage of collisions, which means among the other weather variables, rainfall is the most common adverse weather condition for crash. According to the National Highway Traffic Safety Administration (NHTSA), from 1995 to 2005, there were on average over 6,400,000 vehicle crashes annually in the United States. Twenty-four percent of these crashes were weather-related, which are defined as crashes occurring in adverse weather conditions (i.e., rain, sleet, snow, and/or fog) or on slick pavement (i.e., wet, snowy/slushy, or icy pavement). Each year, nearly 7,400 people are killed and over 673,000 people injured in weather-related crashes. 
Table 1: Percentage of Injury and Fatal Collisions during Selected Weather Conditions (\%)

\begin{tabular}{cccc}
\hline & United States & Great Britain & Canada \\
\hline Clear & 88.1 & 82.0 & 77.9 \\
Snow / Freezing Precipitation & 1.9 & 0.7 & 7.6 \\
Rain & 8.6 & 16.2 & 11.9 \\
Fog / Other reduced visibility & N / A & 1.1 & 0.9 \\
Other & 1.4 & 0.0 & 1.7 \\
Total & 100.0 & 100.0 & 100.0 \\
& & \\
\hline $\begin{array}{l}\text { T(FARS, 1997)-Based on the year 2006-2009 } \\
\text { 2(Edwards, 1996) - Averages based on the years 1980-1993 }\end{array}$ \\
3(Transport Canada, 2000) - Averages based on the years 1996-1998
\end{tabular}

Portland, Oregon experiences a climate effect from the ocean, where annual precipitation is higher than the national precipitation average value. According to crash data from the Oregon Department of Transportation, 16,700 crashes on state highways happened in year 2007 , with $22.2 \%$ of these crashes taking place in weather, and $16 \%$ of these severe accidents occur during rainy days. Therefore, quantifying driving risk under rainy conditions is important for an effective highway safety management system; it can help define the risk level on different sections of highways. If a certain section of roadway is showing a higher crash risk under rainy conditions, it could be information to consider a project to help reduce crash risks, e.g., increasing pavement friction, or a traffic warning signs. This study will focus on relative 
crash risks for Oregon Highway 217 on rainy days. Our goal is to help reduce the occurrence of crashes under severe weather conditions. 


\subsection{LITERATURE REVIEW}

There are several prior studies of the relationship between traffic crashes and precipitation. These studies employ a variety of methods and data sources, and they highlight rain as an important cause behind roadway accidents. Appendix A provides an overview of several studies.

\subsection{Backgrounds}

Walter et al (2003) proposed the concept of evaluating risk theory. He asserts that risk assessment is a scientific process for evaluating the adverse effects caused by a substance, activity, lifestyle, or natural phenomenon. The range of the probabilities of the risk could help to describe an uncertainty of risk assessment precisely. Based on risk theory, it is believed that the risk of having traffic accidents cannot be precisely predicted either, but the trend of the accident risk can be estimated within a certain range of confidence.

In the traffic network, a traffic accident risk can be a combination of probability and consequences of a certain incident, according to Berdica (2002). Therefore, the definition of risk consists of two parts: (1) the probability for the incident to occur and (2) the resulting consequences should the incident occurs. Because of the many variations in the perceptions of different decision makers, different factors are chosen to evaluate the probability and consequences of incidents, leading to different ratings of risk 
probability. Consequently, a risk matrix, as shown in Error! Reference source not found., can be used to explain this definition.

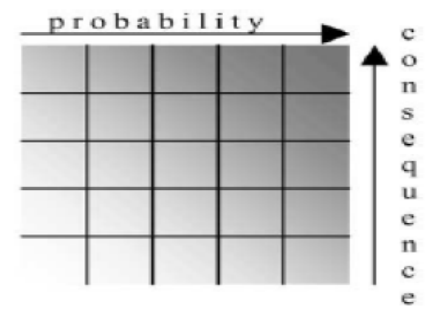

Figure 1: Risk Matrix: combination of probability and consequence (Berdica, 2002)

In this matrix, the probability of incidents increases from left to right; the consequences of incidents grow higher from bottom to top; and the risks for incidents increase as the color goes darker. Berdica explains that the "everyday minor accident" is placed in the lower right hand corner because of its high probability to occur and the low resulting consequences to the system. But a bridge collapse is placed in the upper left hand corner since it has a low probability of occurrence and serious long-term consequences. Because of the various types of traffic crashes, their consequences are widely distributed on the risk matrix. Therefore, many traffic safety researchers focus only on a single axis of the risk matrix and study the probability of having crashes. This approach simplifies the modeling procedure and advances the ability of models to produce traffic crash rates. 


\subsection{Relative Risk Ratio Method}

Many researchers focus on accident risk prediction using different perspectives such as roadway geometric feature data, traffic volume data, accident data and weather related information. Among these perspectives, rainfall and snowfall are recognized as the most common adverse weather conditions. In the past three decades, many studies have been on weatherrelated crash risks and their temporal variations.

Gwynn (1967) first found strong empirical evidence of functional relationships between crash rates and traffic flow. He investigated the relationship between accident risk and hourly traffic flow rate frequency and introduced the frequency ratio method to compare accident rates of passenger cars and trucks on a selected route in New Jersey. He calculated the percentage of total accident involvement and total volume for passenger cars and trucks at different levels of hourly traffic flow rate. Both accidents and injury rates were found to follow a U-shaped pattern, with higher accident and injury rates occurring under low and high hourly traffic flow.

To quantify the crash risk under adverse weather conditions, the relative risk ratio with match-paired method is the most common method today. The most notable study on this subject comes from Andrey, Mills and Vandermodlen in a series of published documents (2003) (1993), in which a standardized method was developed to compare the role of precipitation in the relative risk of crashes and injuries for different places and time periods. 
Andrey (1993) applied the match-paired method for the cities of Calgary and Edmonton, Canada during years 1979-1983. He examined a total of 169 rain events and over 15,000 accidents. He found that the higher proportion of wet-road versus rain-related accidents during the event periods was related to the temporal and spatial intermittence of rainfall event in the area. For the post-event periods, wet road conditions persist for some time due to pavement drying times. The overall relative risk ratio throughout the event periods is 1.7 , which means that overall risk during rainfall conditions is $70 \%$ higher than normal conditions. Due to the lingering effects of wet road conditions, more than one-third of the accidents that occur in the first hour of the post-event period take place on wet roads. His data suggest that the accident risk returns to normal an hour after rainfall ceases.

Andrey et al. (2003) explored temporal variations in weather-related collision and injury risk in Ottawa, Canada over the period 1990-1998. He estimated and compared the relative risk ratio of collision and injury during precipitation relative to normal seasonal conditions. For both temporal and spatial by time period, he found that both winter precipitation and rainfall precipitation significantly increased the risk of a collision and injury. The estimates for winter precipitation in Ottawa (1.47 for collisions and 1.21 for injuries) and rainfall (2.12 for collisions and 1.69 for injuries) fell within the upper range of his published values.

ElDessouki at al. (2004) applied a relative risk ratio not only on weather conditions, but also on traffic volume data from automatic traffic stations. 
They found that accident risks increased in severe weather, with snowfall having higher accident rates than rainfall conditions. By developing an exponential model for relative risk ratio with variable volume-to-capacity, he showed that the accident rate in non-precipitation conditions could be smaller than precipitation conditions only if the traffic volume reduced according to the reduce capacity.

The latest study was by Sun (2010) using crash data and radar rainfall data from the National Weather Service WSR-88D NEXRAD Doppler Radar system, which provided a comprehensive dataset with large spatial coverage, high spatial resolution and continuous temporal sampling to quantify the relative crash risk with a matched paired method. She found out that crash and injury risks increases during rainy weather conditions. The level of risk varies by the types of roadways and locations. Crashes occurring during rainy hours were more likely to be serious than non-rainy conditions.

\subsection{Gaps in Current Research}

However, there is still a lack of studies which apply high-resolution data with crash analysis. With development of weather detection facilities and technology, the rainfall weather data can be detected into more comprehensive ways. The traditional weather station measured rainfall intensity at point locations (usually airports), in hourly time intervals and covering a limited location. Lack of high-resolution rainfall data with a continuous spatial coverage impacts the reliability of any rainfall-accident 
analyses, especially in regions where rainfall is characterized with high variability. Ideally, to correlate rainfall to accidents, one would need specific rainfall information at the location where the accident has occurred. The advanced National Weather Service Next Generation Weather Radar Doppler (NEXRAD) system provides more comprehensive information, providing more spatial coverage over any particular highway and better time resolution. The next chapter will quantify these different weather data, define the advantage for having different weather data sources; it also described the traffic data and crash data source used for this study. 


\subsection{DATA SOURCES}

This chapter presents data sources that will be used in the research, and the procedures for processing the data. The study location, weather data and crash data for this highway segment are described in this chapter.

\subsection{Study Location}

The freeway system in the Portland metropolitan region consists of several Interstate and U.S. highways and state routes. Oregon 217 is a 7 mile corridor which serves the western suburbs of Portland. It is a limited access freeway that connects U.S. Route 26 and Interstate 5 (see Figure 2).

Because of its special location, traffic on Oregon 217 southbound is frequently heavy, especially during rush hour. Due to several design problems, the Oregon Department of Transportation (ODOT) has also been considering a major overhaul of this route. For example, the designs of ramp distance are frequently short and do not allow for gentle acceleration to freeway speeds. Many on and off ramps also appear within a very short distance of each other (sometimes less than $1 / 4$ mile) (See Figure 2). Once on the freeway, drivers find themselves hastily jostling for position before they must exit. For all these reasons, Oregon 217 has been chosen as a route to investigate for this study. 

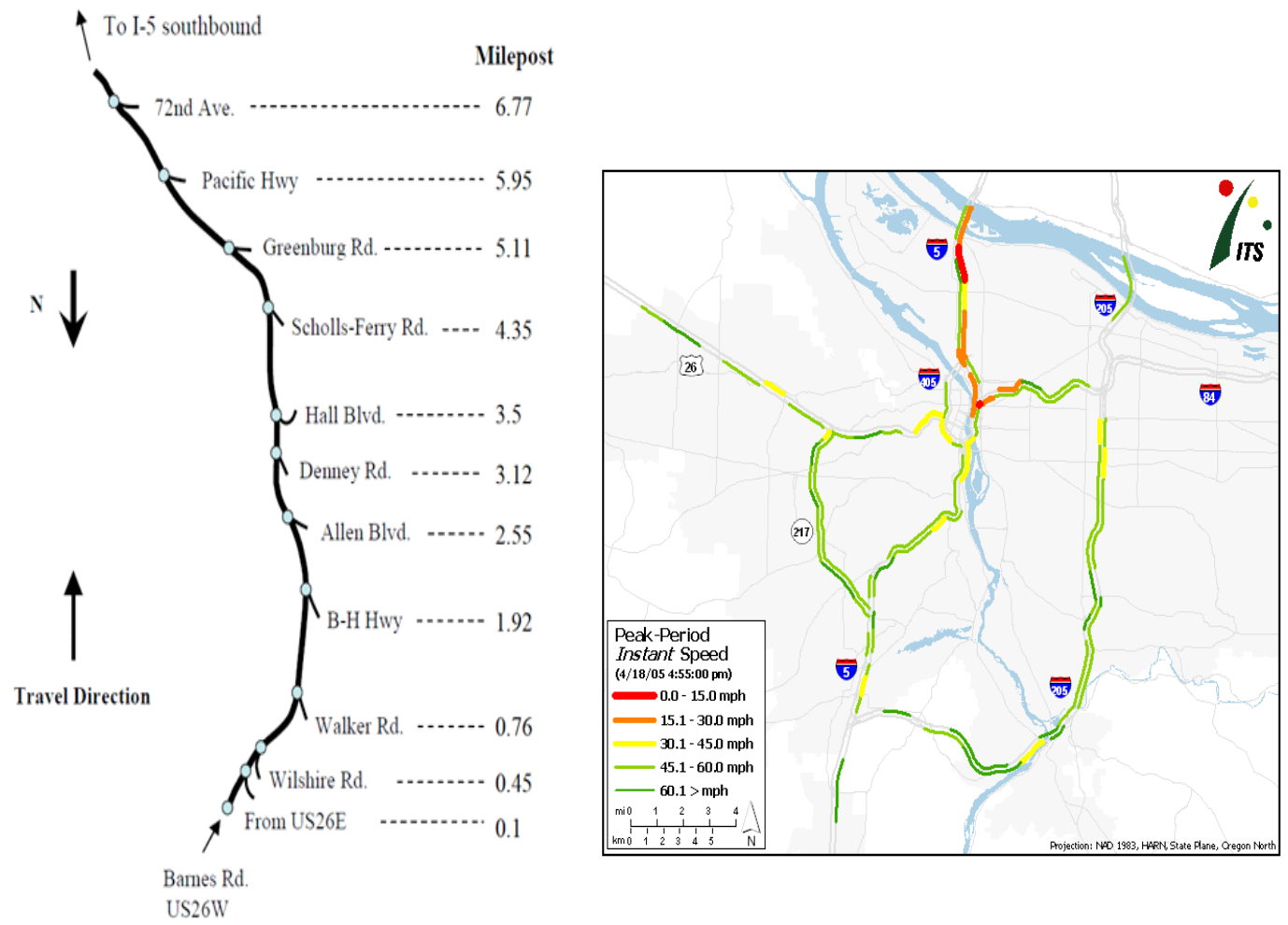

Figure 2: Maps of Oregon 217 Soundbound Direction

\subsection{Weather Data Sources}

\subsubsection{PORTAL Data Archive- Weather Satiation Data}

The Portland Oregon Regional Transportation Archive Listing (PORTAL—see http://portal.its.pdx.edu) is a transportation data archive created to help improve understanding of Portland, Oregon's transportation system performance.

As shown in Figure 3, PORTAL has been gathering and archiving different kinds of transportation data since 2004 that can later be retrieved and output over various time and space scales. There are approximately 600 
inductive loop detectors on Portland's metropolitan freeways which are the primary data sources for PORTAL. Traffic data collected at 20-second intervals is streamed to the PORTAL servers. This data includes count, occupancy and time means speed in each lane. PORTAL also includes weather conditions in Portland from automated weather stations dating back to 2002. The key weather metrics are temperature, visibility, wind speed, and rainfall.

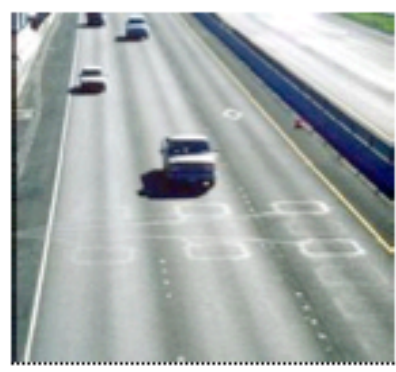

Loop Detactor Data 20 s coum, lane cecupengy, speed firm boc datectors (1.2 ml spacing)

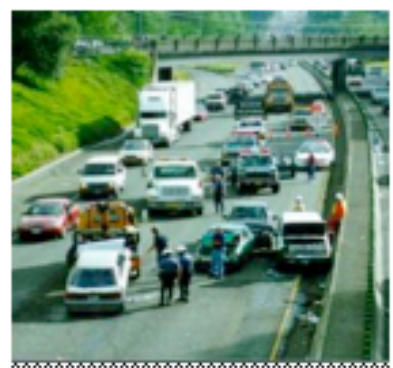

Incldent Data

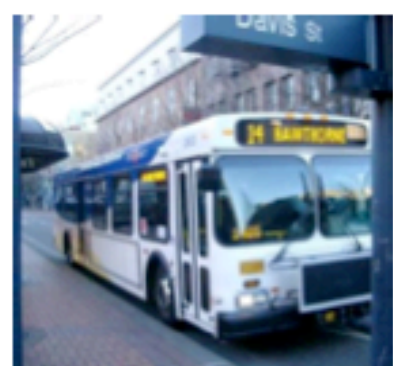

Bus Data 1 your stop lovel ate $140,000,000$ rows

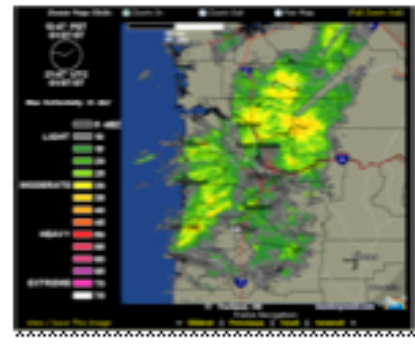

Weather Data Houty data dino $2 \mathrm{mo4}$

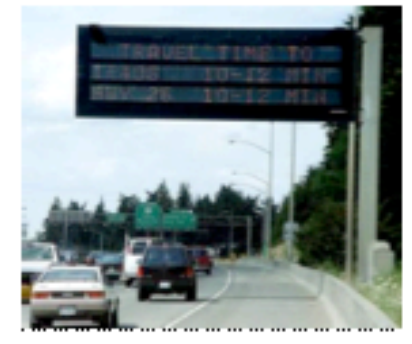

VMS Data 19 Vis since 1809

Figure 3: PORTAL Data Archive Contents

(Bertini at al. 2005)

Traditionally, weather data is measured from stations at major airports. These stations observe atmospheric conditions and carry out measurements 
including temperature, wind speed, wind direction, and precipitation amounts. In the Portland region, there are three weather observation stations. They are located at Portland International Airport and the suburbs of Hillsboro and Troutdale, which are located west and east, respectively, of the city of Portland (Bertini et al. 2005).

\subsubsection{Aggregation PORTAL Weather Station Data}

PORTAL weather station data are available at (http://portal1.its.pdx.edu/archive/weather.php). Figure 4 shows an example of weather data on January 3, 2007, for Highway 217 in the southbound direction. PORTAL provides hourly and daily weather data types. However, hourly weather data contain erratic readings. On January 3rd, for example, there were five readings with very different rainfall values, ranging from 0 to 0.15 inches, between 00:41 to 00:58. For the purpose of this study, only the maximum rainfall intensity in each hour is used for year 2007.

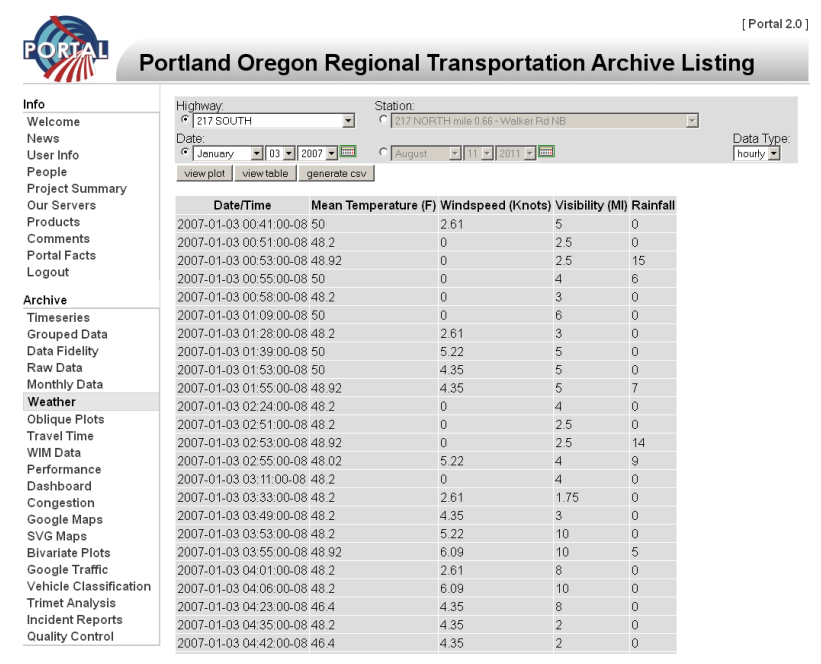

Figure 4: Example of PORTAL Weather Data 


\subsubsection{Next Generation Weather Radar Doppler (NEXRAD) Data}

Next Generation Weather Radar (NEXRAD) Doppler weather radar is a commonly used weather detection system since the 1990s. It detects precipitation, atmospheric movement and wind. In United States, there are 141 Weather Surveillance Radar and 1998 Doppler (WSR-88D) units across the 48 contiguous states. For Oregon, there are three National Doppler Radar sites, which are located at Portland, Medford and Pendleton. Figure 5 shows radar installations across the country. Each radar has a nominal range of 230 $\mathrm{km}$ (about 143 miles), although this can be affected by topography and atmospheric conditions.

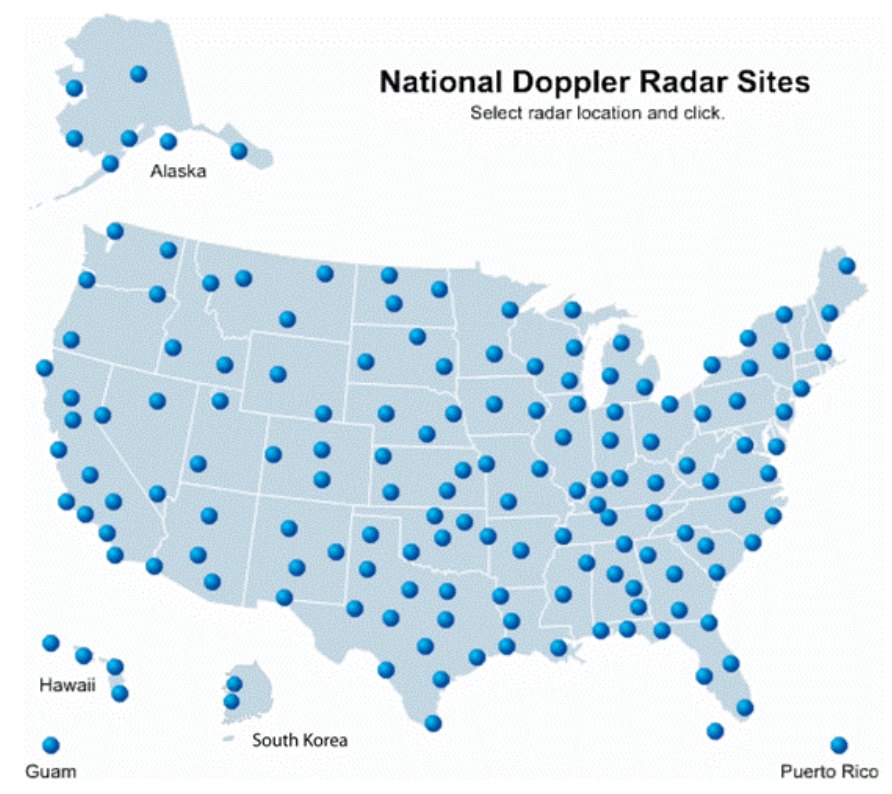

Figure 5 : National Doppler Radar Sites 
Three functional components make up the WSR-88D: Radar Data Acquisition (RDA), Radar Product Generator (RPG), and the Open Principal User Processor (OPUP). NEXRAD product Level II data is provided in real time directly from the NEXRAD Radar Data Acquisition (RDA) unit. In this study, NEXRAD system level II data will be used for providing rainfall intensity values. Because all the NEXRAD data are produced by the National Center for Environmental Prediction (NCEP), these data and derived products are available at no cost through the National Climatic Data Center on NOAA website (http:/ / www.ncdc.noaa.gov/nexradinv/).

The NEXRAD Level-II data contains three basic meteorological metrics: reflectivity, mean radial velocity, and spectrum width. The weather radar is designed to scan the atmosphere with a pulsed rotating microwave beam out to a range of 143 miles. The reflected microwave energy can be used to quantify precipitation levels, such as rainfall, hail, and storms in the atmosphere. The stronger the reflections are, the greater the precipitation in the atmosphere. Reflectivity is represented as the amount of transmitted power/energy returned to the radar receiver, in the unit of dBZ. The base reflectivity can be converted into rainfall rates using a simple equation shown below, which has been proven from more than 20 years of observation:

Rainfall rate $=\left(10^{\wedge}(\mathrm{dBz} / 10) / 200\right) \wedge 0.625$

$\mathrm{dBz}$ : the base reflectivity detected from WSR-88D NEXRAD radar Rainfall rate: in unit of $\mathrm{mm} / \mathrm{hr}$ 
3.2.2.1 Processing Radar Data

Radar data is supplied as volume-scan files. Each file contains data from the WSR-88D radar of all sweeps for a period of time. Reflectivity is based upon the operation mode of the radar at the time when the image is generated. There are two operation modes: clear air and precipitation mode. In clear air mode, radar is most sensitive, and images are updated every 10 minutes. When precipitation mode is occurring, the radar is not as sensitive as clear air mode, because the rain provides a large returning signal. In precipitation mode, images updates occur more frequently, around five to six minutes apart. For this study, aggregated radar is studied in ten minute intervals (independent of operation mode), and the maximum reflectivity value for every ten minutes is used.

\subsubsection{Step One: NOAA toolkit}

For processing the NEXRAD level II data, NOAA's Weather and Climate Toolkit is an application that provides simple visualization and data export of weather and climatologically archived data at NCDC. The climate Toolkit also provides access to weather and climate web services provided by NCDC and other organizations. The Viewer provides tools for displaying custom data overlays, Web Map Services (WMS), animations and basic filters. The export of images and movies is provided in multiple formats. As seen below, Figure 6 shows the radar sweep reflectivity on January 1, 2007, 16:39:19 
GMT time. For Portland, Oregon all radar data had to be adjusted 7 hours to match with crash and other data sources.

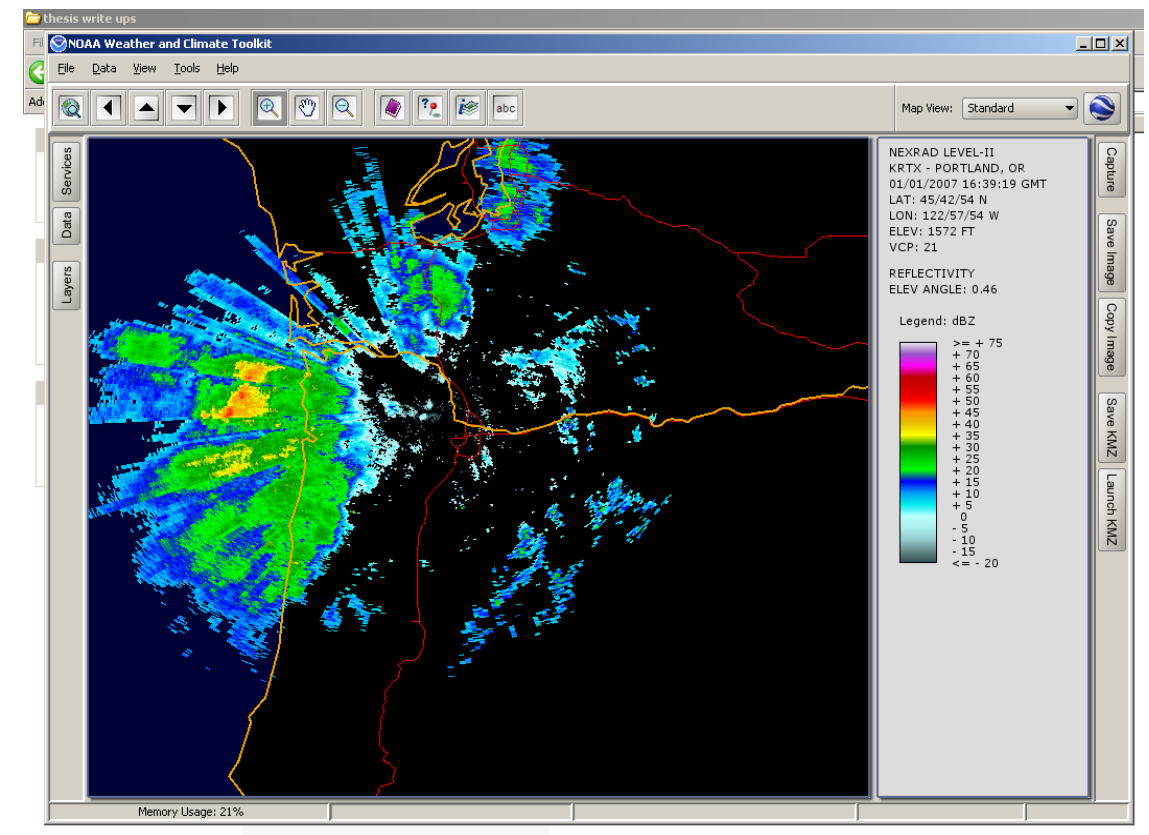

Figure 6: Radar Sweep View Display

\subsubsection{Step Two: Converted by ArcGIS}

NOAA weather toolkit data exporter function exports vector files into points, lines and polygons, as well as raster grid formats. After conversion by the toolkit, the radar data can be read by ArcGIS Map application. For each sweep time, radar can provide reflectivity values as shapefile in both polygon and point centroid files as about $1^{*} 0.5 \mathrm{~km}^{\wedge} 2$ grid system as Figure 7 shown below within 10 minutes resolution after aggregation sweep time value. 


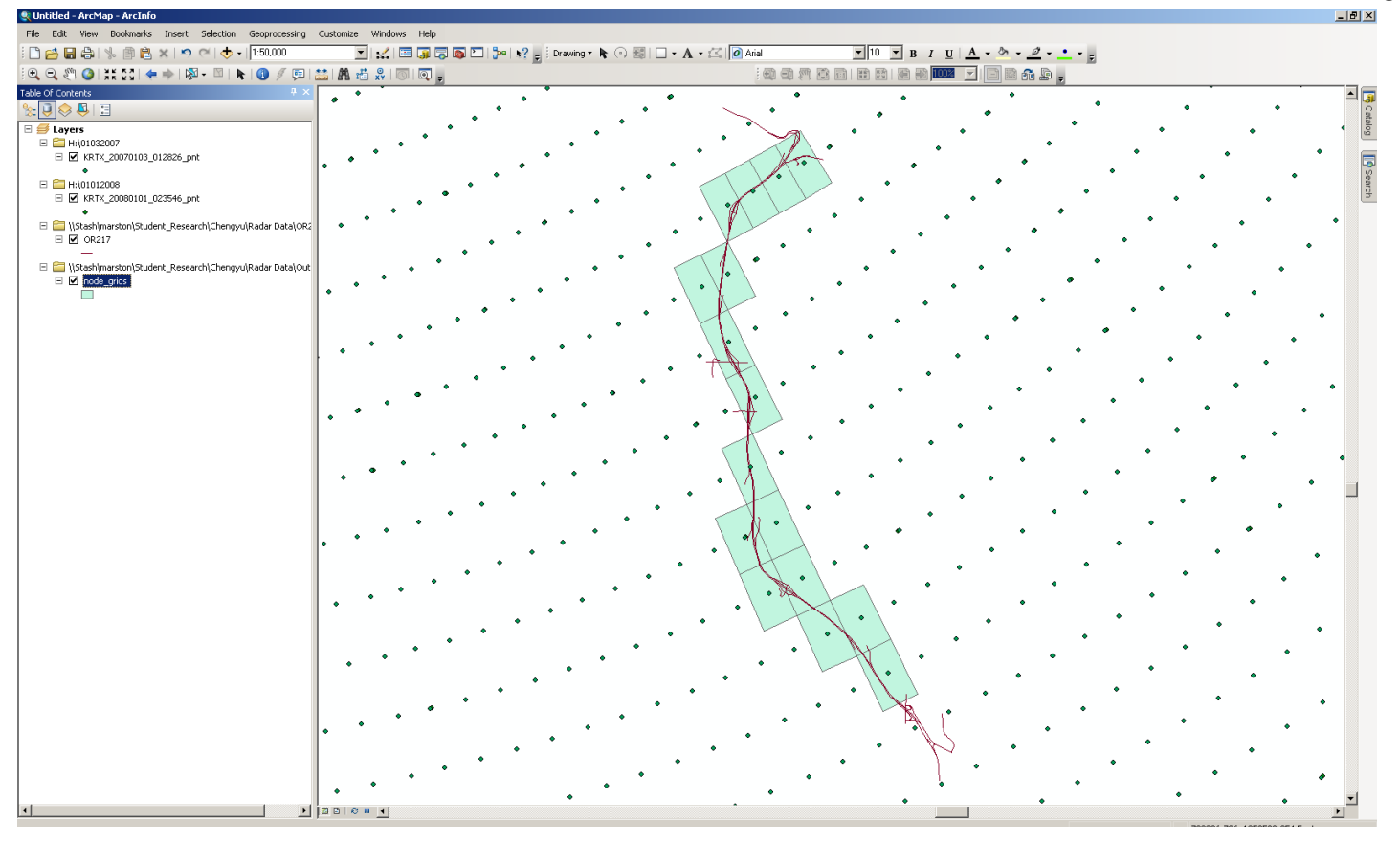

Figure 7: Converting into ArcGIS Map

For the purpose of this study, NEXRAD radar data in year 2007 is used. As shown in Figure 7, highway Oregon 217 is covered by 16 radar pixels, each pixel independent precipitation readings, even for the same rainfall events. Therefore, after aggregating for every ten minutes intervals, there are 840,960 radar data has been collected for year 2007.

\subsubsection{Visualized NEXRAD Radar Data}

As discussed earlier, radar can be used to monitor the rate of rainfall $(\mathrm{mm} / \mathrm{hr})$ in 10 minute intervals over a minimum pixel size of $.5 \mathrm{~km}^{\wedge} 2(.6 x .3$ miles $\left.^{\wedge} 2\right)$. The amount of rainfall can be categorized into six groups: no precipitation, mist, trace, light moderate and heavy, with ranges based on NOAA NWS NEXRAD manual as $0,<=0.1538,<=0.3158,<=2.734,>2.734$, 
respectively (units in $\mathrm{mm} / \mathrm{hr}$ )). Monthly plots of all rainfall precipitation intensity are shown in Appendix B, providing a visual mapping of rainfall throughout the whole year. From these maps, it is clear that January, November and December had heavier rain than other months.

\subsubsection{PORTAL VS. NEXRAD Weather Data}

Table 2 shows the summary of two weather data sources. To test if the PORTAL weather is equal with NEXRAD radar data, a paired t-test was conducted to find if there is significance between the means precipitations. Because of the finer resolution of radar data, in order to match with Oregon 217 traffic information, according to Figure 2, ten milepost stations have been chosen to understand the changes of precipitations along the highway.

Table 2: Summary of NEXRAD radar and PORTAL weather data

\begin{tabular}{lcc}
\hline & NEXRAD Level II & PORTAL \\
\hline Duration & $1995 / 06 / 21-2011 / 08 / 05 /$ & $2002 / 01 / 01$-present \\
Intervals & Every 5 to 10 minutes & Hourly \\
Spatial Scale & $1 \mathrm{~km} * 0.5 \mathrm{~km}$ & 3 Airports \\
Data Counts & 840,960 & 8760 \\
\hline
\end{tabular}

To conduct this paired t-test, an assumption of equal variances, and normal distributed for both weather data are to be applied. A confidence level of 0.95 was used in the calculation. The result of t-test summarized for each milepost is shown in Table 3. As seen, the mean precipitation for NEXRAD is larger than PORTAL, which means radar detecting more rainfalls than 
weather stations. Due to the numerous number of data we used, the degree of freedom (df) for data is 8759 for each milepost, and the $t$ critical value for two tail result is 1.96, according to the t-stat values in Table 3, NEXRAD data is significantly different from PORTAL data. Figure 8 is the example of the changes of precipitation for both weather sources; as shown, both weather data following a similar rainfall patterns, but that NEXRAD radar data detects much higher value than weather station PORTAL data. Figure 9 shows the PORTAL and radar weather precipitations reading comparisons at the sample location (Hillsboro Airport) in 24 hours real time, and also a comparison of average precipitations for the freeway Oregon 217 using radar data using the same time period. As shown, both weather data provide the similar rainfall intensity tend throughout the day, however, the real-time radar weather at location Oregon 217 showing much more intense precipitations at some time of day, meaning that rainfall intensity is changing by locations.

Table 3: Paired T-test Result for Different Milepost

\begin{tabular}{lcccccccccc}
\hline MP & 0.45 & 0.76 & 1.92 & 2.55 & 3.12 & 3.5 & 4.35 & 5.11 & 5.95 & 6.77 \\
\hline $\begin{array}{l}\text { Mean } \\
\text { Radar } \\
\text { (mm/hr) }\end{array}$ & 0.27 & 0.30 & 0.33 & 0.23 & 0.24 & 0.23 & 0.29 & 0.27 & 0.28 & 0.28 \\
$\begin{array}{l}\text { Mean } \\
\text { PORTAL } \\
(\mathrm{mm} / \mathrm{hr})\end{array}$ & 0.11 & 0.11 & 0.11 & 0.11 & 0.11 & 0.11 & 0.11 & 0.11 & 0.11 & 0.11 \\
$\begin{array}{l}\text { Mean } \\
\text { Diff. } \\
(\mathrm{mm} / \mathrm{hr})\end{array}$ & 0.15 & 0.19 & 0.22 & 0.12 & 0.12 & 0.12 & 0.17 & 0.16 & 0.16 & 0.17 \\
$\mathrm{t} \mathrm{stat}$ & 23.0 & 24.7 & 25.5 & 21.1 & 20.2 & 19.6 & 22.2 & 21.7 & 21.9 & 21.0 \\
$\mathrm{P}$ & Sig & Sig & Sig & Sig & Sig & Sig & Sig & Sig & Sig & Sig \\
\hline
\end{tabular}




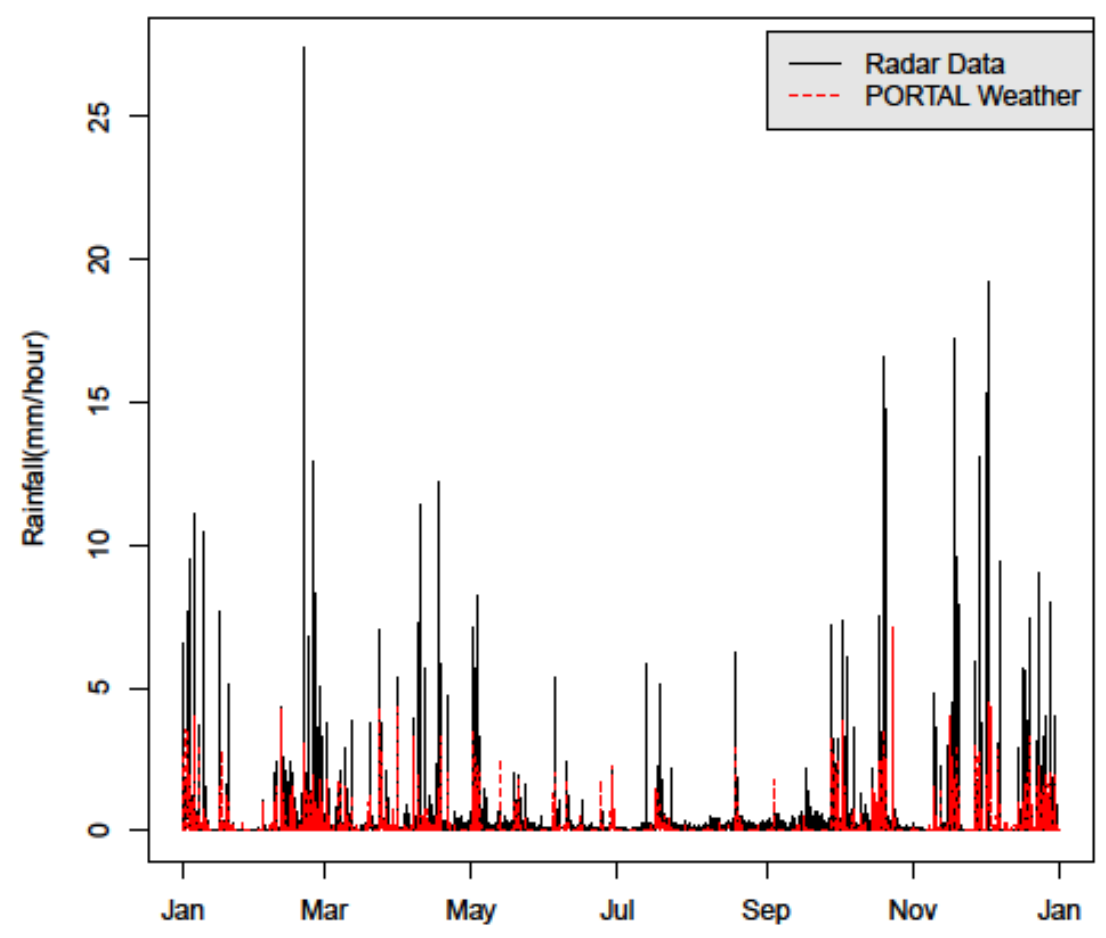

Figure 8: PORTAL Weather Data and Radar Data at Milepost 0.76 in 2007

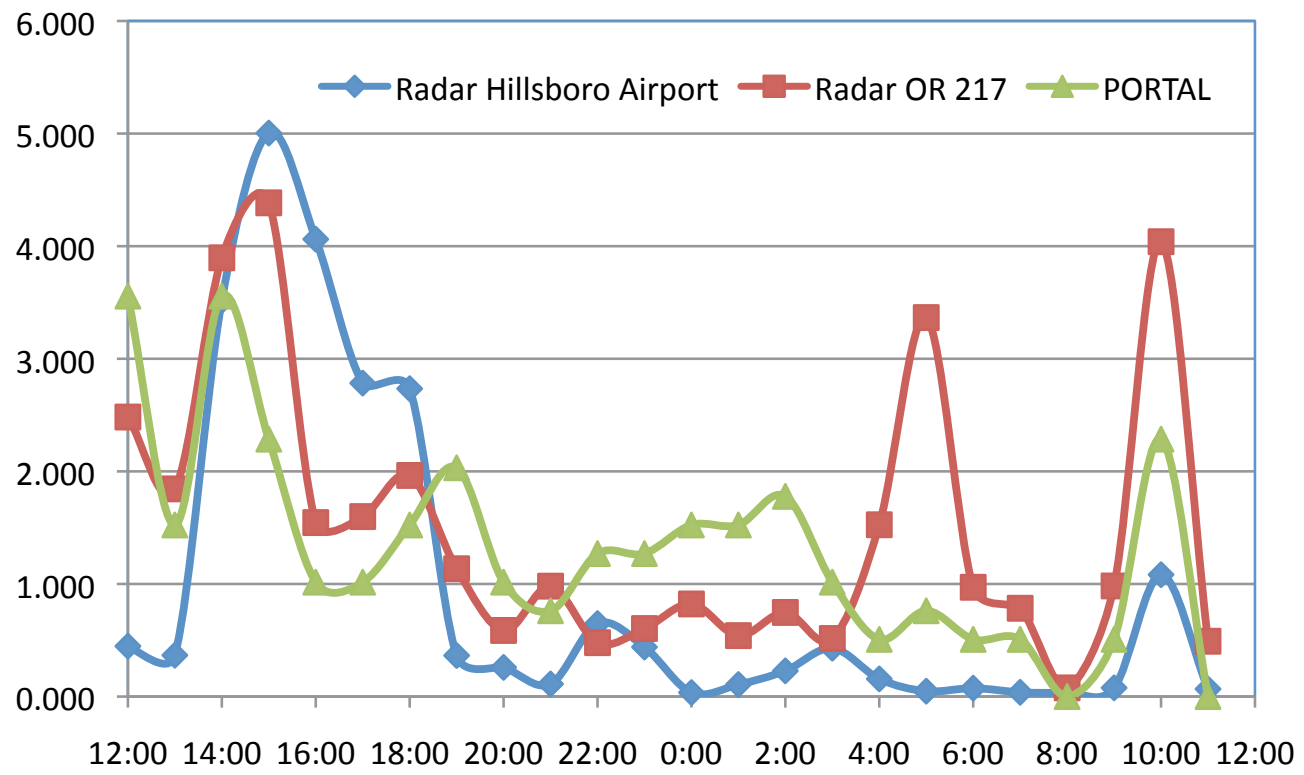

Figure 9: Weather Sample at Hillsboro Airport 


\subsection{Crash Data}

Crash data for Oregon 217 is derived from Oregon Traffic Safety Data Archive (OrTSDA). OrTSDA is an archived online safety data based on Oregon DOT crash data. ODOT crash data is collected from police report, including crashes records such as crash date and time, location, weather and roadway information when crash occurred, vehicles and vehicle occupants' information, as well as severity of the injury and types of crashes. Crashes in year 2007 were used for this study. Based on police records, 214 crashes occurred on Oregon 217, with 44 crashes happening under rainy conditions. Figure 10 and Figure 11 show a summary of different crash types, with property damage only (PDO) crashes as the most common crash and December having the highest number of crashes.

\section{Types of Crashes}

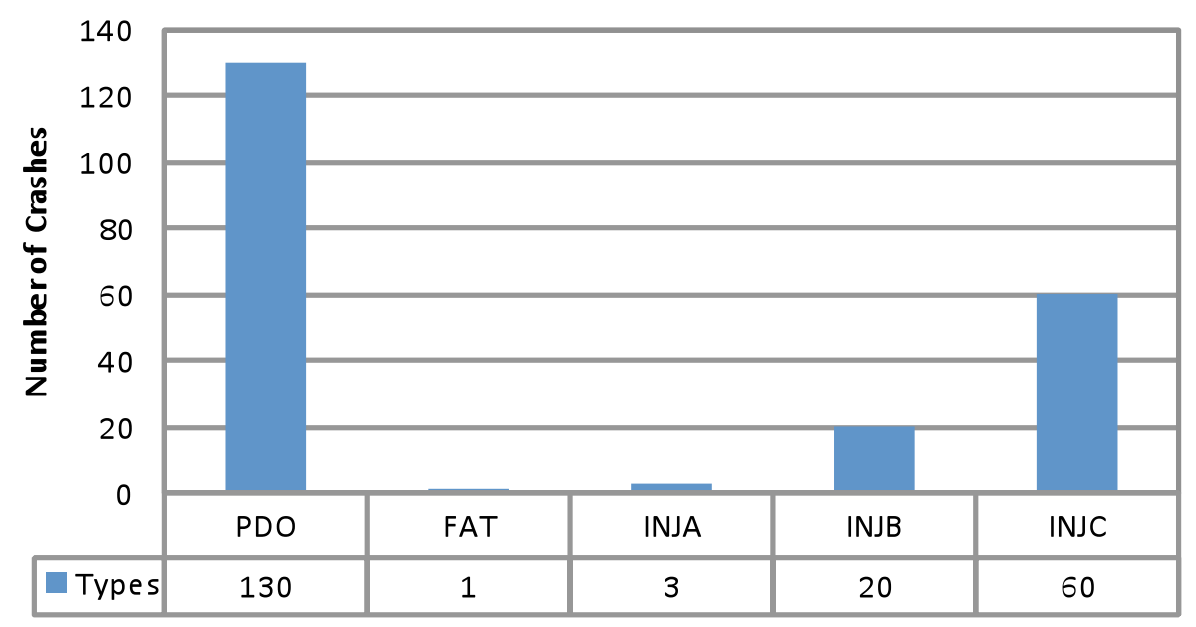

Figure 10: Summary of Types of Crash for Oregon 217 


\section{Seasonal Pattern of Crashes}

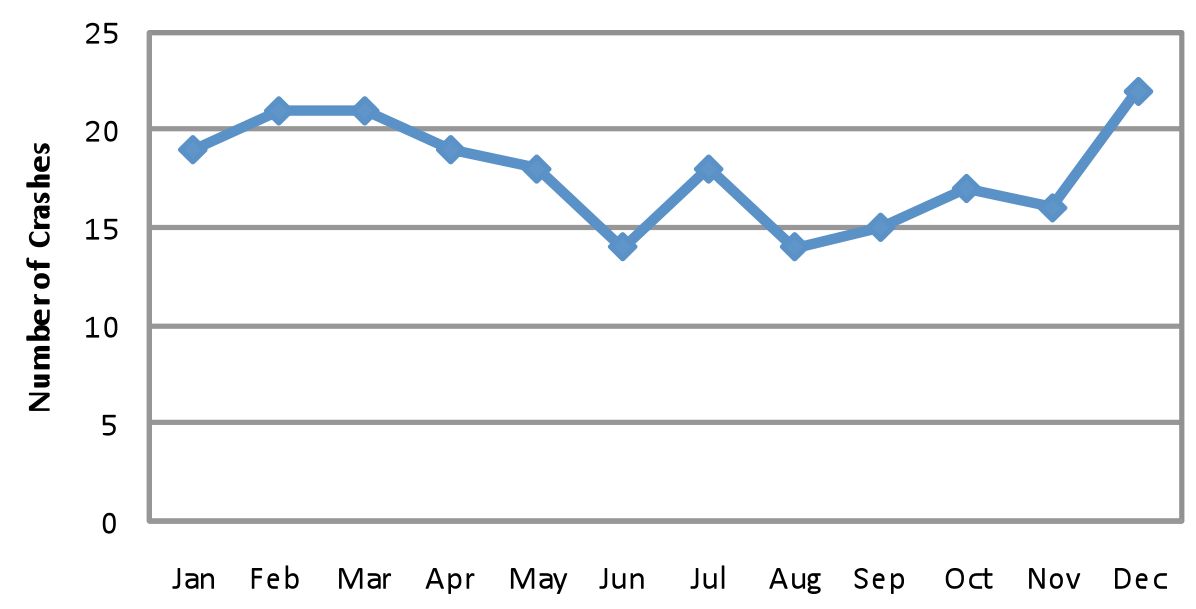

Figure 11: Seasonal Patterns of Crash for Oregon 217 in year 2007

The summary of crashes occurring during rainy condition is listed in Table 4. As shown, based on different weather data sources, records of crashes occurred in rainy days are different. The weather condition on police reports were defined by policemen, as shown in the table, police report has the highest number and percentage; and other two weather data report rainy crash nearly the same, meaning there is a bias from police report. Table 5 indicates the monthly distribution of rainy day crash, for both weather data December has the highest number of crashes. Appendix F visualized the crash distribution for NEXRAD radar rain precipitation respectively to locations; it provides visualized images of crashes with the amount of precipitation. 
Table 4: Summary of OR-217 Crashes for Rainy Conditions, 2007

\begin{tabular}{ccc}
\hline & $\begin{array}{c}\text { Number of Crashes Occurred } \\
\text { Under Rainy Days }\end{array}$ & $\begin{array}{c}\text { \% Crashes Occurred } \\
\text { Under Rainy Conditions }\end{array}$ \\
\hline Police Report & 44 & $20.60 \%$ \\
PORTAL & 32 & $15.00 \%$ \\
Radar & 33 & $15.40 \%$ \\
\hline
\end{tabular}

Table 5: Monthly Distribution of Crashes on OR-217 in Rainy Days, 2007

\begin{tabular}{c|cc}
\hline & Radar & PORTAL \\
\hline Jan & 0 & 0 \\
Feb & 5 & 7 \\
Mar & 3 & 5 \\
Apr & 6 & 6 \\
May & 1 & 0 \\
Jun & 0 & 1 \\
Jul & 3 & 1 \\
Aug & 2 & 0 \\
Sep & 0 & 1 \\
Oct & 4 & 3 \\
Nov & 2 & 1 \\
Dec & 7 & 7 \\
\hline Sum & 33 & 32 \\
\hline
\end{tabular}

The next chapter will discuss the methods applied for exploring the crash risk on freeway OR-217. 


\subsection{METHODOLOGY}

This chapter provides the methodology will be used for analyzing the relationships between occurring crashes and rainfall events.

\subsection{Relative Risk Ratio}

Based on relative risk analysis, the matched-paired method is applied in the study, for the purpose of comparing crashes at the same location under a similar environment. This method has great advantages; it minimizes the effects of other factors when crashes occur. For instance, the driver's behavior, time of the day, time of the week, roadway design, traffic volume and travel speeds represent other factors.

In this study, time periods with rain are defined as "event periods". They will be compared against time periods with no rain called "control periods". Both periods will be compared at the same time of the day and same day of the week. Event periods are required to experience rainfall for at least for 2 hours, and rainfall intensity must meet or exceed threshold of $0.20 \mathrm{~mm} / \mathrm{hr}(0.00787 \mathrm{in} / \mathrm{hr})$. Regardless of the weather data source, all event and control periods are compared one week apart.

Careful selection of match-paired event and control periods is important for this study, because the basic assumption of this method is to ensure isolation of the other variables which influence crash occurrences. It is important to keep non-weather factors between event and control periods similar. In this study, event periods are selected according to the criteria 
described in Table 6, the two-hour minimum rainfall with certain amount of precipitation is to ensure that the road surface is wet. The control periods are matched for the same time of the day, duration, and day of the week of the rainfall event, as demonstrated in Table 6. All the matched-pairs will be developed for a seven-mile section of Oregon-217 and within all 16 radar pixels.

Table 6 : Criteria for Selecting Event and Control Periods

\begin{tabular}{lc}
\hline \multicolumn{1}{c}{ Criteria for Events (Rain) Periods } & Criteria for Control (No Rain) \\
& Periods \\
\hline Rainfall must meet or exceed precipitation detection & No rainfall \\
threshold of $0.20 \mathrm{~mm} / \mathrm{hr}$ for at least 2 hours. & No rainfall for 6hrs preceding the \\
\hline A rain break up to one hour is allowed, as long as there is & period \\
\hline rain before and after the break & \\
\hline
\end{tabular}

\section{No holidays are considered for both period}

ElDessouki (2004) conducted a study based on estimating the relative risk of experiencing accidents under different combinations of weather conditions and traffic volume situations. He developed a value called the Relative Risk Ratio (RRR), which is the adjusted risk of observing accidents given a fixed value of traffic flow rate and weather conditions. This method can be used for estimating the relative accident risk level for a roadway segment, and to monitor a road network and identify potentially hazardous traffic flow and weather conditions on them, and mitigate them through 
implementation of a traffic control or driver alert strategy. By definition, the relative risk is calculated as:

$$
R R=\frac{N_{e}}{N_{e}}
$$

Where,

Ne: number of crashes in event, rain

Nc: number of crashes in control, no rain

In following chapter will focus on results after applying the matchpaired method, and the analyses in term of improve travel safety issues. 


\subsection{RESULTS}

After applying the match-paired approach by using NEXRAD radar ten-minute precipitation data, there are 1,219 pairs of event and control periods were identified for the year 2007. However, the occurrence of a crash is a relatively rare event and at spatially and temporally disaggregated level, only 26 of match-pairs with crashes occurred. Among those, 15 of crashes occurred under rainy condition, and 11 of them happened no rains conditions, as shown below. Therefore, relative crashes risk ratio equals 1.346 , which indicates a relatively higher driving risk under rainy conditions.

\section{Table 7 : Result of Relative Crash Risk for Different Weather Data}

\begin{tabular}{ccccc}
\hline $\begin{array}{c}\text { Weather } \\
\text { Source }\end{array}$ & $\begin{array}{c}\text { Number of Matched-Paired } \\
\text { with Crashes }\end{array}$ & RRR & $\begin{array}{c}\text { Crash in } \\
\text { Event Period }\end{array}$ & $\begin{array}{c}\text { Crashes in } \\
\text { Control Period }\end{array}$ \\
\hline NEXRAD & 26 & 1.364 & 15 & 11 \\
\hline
\end{tabular}

With the compressive radar data, the spatial variation for each mile post on Oregon 217 is depicted in Table 8. The spatial analysis unit is defined by radar pixel combined into nearest traffic detectors where travel on-ramps usually are in this case. As shown there are two on-ramp points with relative risk ratio higher than 1 , means rainy fall is important factors causing crashes. The relative risk ratio is largest at MP 2.55 station Allen Blvd (from BeavertonHillsdale highway to Allen Blvd), which may result from differences in lengths between traffic on-ramps. The distances between two adjacent on- 
ramps are less than one mile, except from MP 0.76 to MP 1.92. The relative risk ratio is higher right after that segment, which would be caused from the waving traffic flow issues during rainy conditions.

\begin{tabular}{ccccc}
\multicolumn{5}{c}{ Table 8 : Relative Crash Risk Ratio by Mile Post } \\
\hline Mile Post & Total Crash & Total Crash & Relative Risk & \\
\hline 0.45 & 1 & 0 & Ratio & Length of Road \\
0.76 & 1 & 0 & - & 0.45 \\
1.92 & 2 & 0 & - & 0.31 \\
2.55 & 4 & 1 & 4 & 1.16 \\
3.12 & 1 & 2 & 0.5 & 0.63 \\
3.5 & 1 & 2 & 0.5 & 0.57 \\
4.35 & 1 & 0 & - & 0.38 \\
5.11 & 0 & 0 & - & 0.85 \\
5.95 & 2 & 1 & 2 & 0.76 \\
6.77 & 2 & 5 & 0.4 & 0.84 \\
\hline
\end{tabular}

Figure 12 shows the three year (from 2005 to 2007) crash distribution by each milepost. As shown, for three year average crashes at milepost 2.55 has the highest number of crashes occurred under rainy conditions than other locations, and also is the only station crash increased from year 2005 to 2007. 


\section{Crashes Occurred in Rainy Conditions}

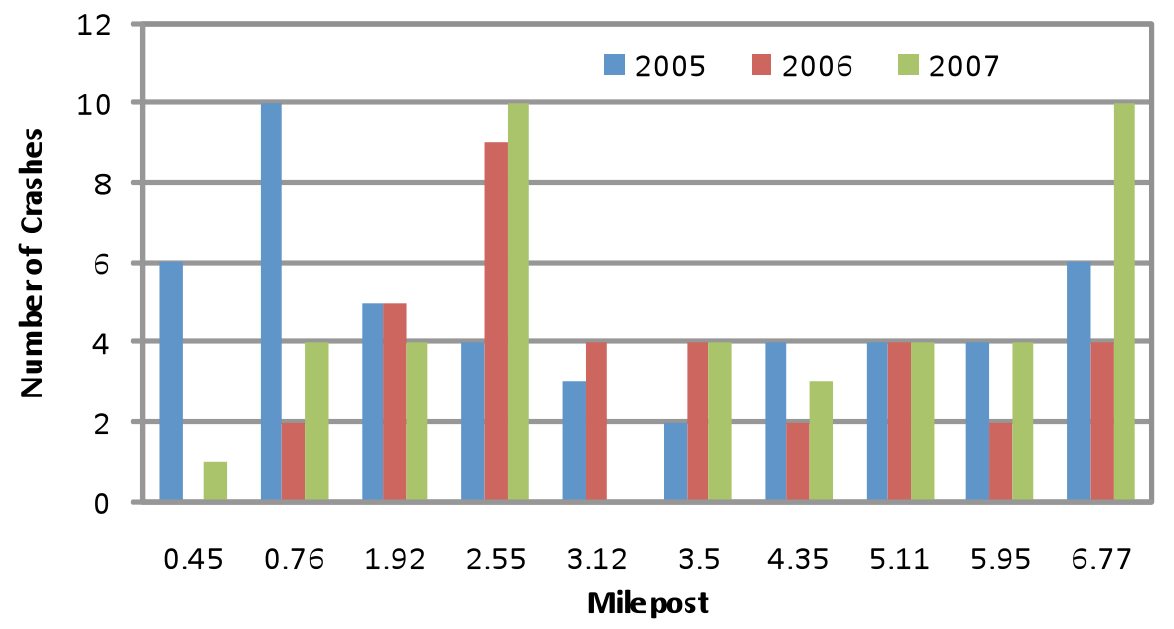

Figure 12: Number of Crashes on OR-217 by Milepost Rainy Conditions

The severity analysis is very important in terms of traffic safety. Table 9 summarizes severe crashes under the match-paired method using NEXRAD data. Rainy condition has a relative risk ratio greater than one, indicating a higher crash risk, especially for property -damage - only crash (PDO).

Table 9 : Severity Analysis with Match-paired by NEXRAD Radar Data

\begin{tabular}{cccccc}
\hline & PDO & INJA & INJB & INJC & INJ(A+B+C) \\
\hline Rain & 13 & 0 & 1 & 2 & 3 \\
No Rain & 8 & 1 & 0 & 2 & 3 \\
RRR & 1.625 & 0 & - & 1 & 1 \\
\hline
\end{tabular}


The traffic volume and speed on OR 217 are applied into matched paired method, to understand how crash impact with traffic performances. Both weather conditions and crash occurrence could impact the traffic performance, therefore, crashes occurring in the event and control are separated into two groups to explore the impacts of weather, crashes and traffic. Table 10 shows the average traffic volume changes when crash occurred under the event and control periods. In both cases, the volume is slightly higher in no rain days (or control periods), which means more traffic at dry conditions, no matter whether or not there is an accident occurring. Same patterns on travel speed table, speed is slightly higher under control (dry) condition, no matter when crash occurred. Therefore, in both cases traffic performances did not change dramatically when crash occurred, but when it's raining, driving speed is slightly lower than dry condition.

Table 10: Crash Occurrence with Traffic Volume (in vplph)

\begin{tabular}{ccc}
\hline & $\begin{array}{c}\text { Average Volume in } \\
\text { Event }\end{array}$ & $\begin{array}{c}\text { Average Volume in } \\
\text { Control }\end{array}$ \\
\hline Crash Occurred in Event & 932 & 959 \\
Crash Occurred in Control & 502 & 531 \\
\hline
\end{tabular}


Table 11: Crash Occurrence with Traffic Speed (in mph)

\begin{tabular}{ccc}
\hline & Average Speed in Event & Average Speed in Control \\
\hline Crash Occurred in Event & 56.0 & 56.6 \\
Crash Occurred in Control & 53.6 & 53.8 \\
\hline
\end{tabular}

The study conclusions and future research will be discusses in following chapter. 


\subsection{CONCLUSIONS}

This study quantifies the two different weather data and weatherrelated driving risks during rainy condition. The advantages of using NEXRAD radar data that contains weather information with finer resolution in both time and locations, gives more details of the rainfall events. However, NEXRAD Level II data is not quality controlled and might overestimate some rainfall events.

After applying the matched-pair approach on Oregon 217 in year 2007 with crash and weather information, the results indicate a higher crash risk when driving under rainy conditions. The quantitative results also reveal that driving risk level varies by the locations and time of the day. For Oregon 217, milepost 2.55 has the highest relative risks driving under rainy conditions. In terms of severity of crashes, PDO crashes occurring higher risks under rainy hours. The result of the crashes characteristic analysis could help to reduce the crashes occurrence at relative problem location, for example, increasing the pavement friction at milepost 2.55 to help reduce driving risk under rainy days.

Using NEXRAD radar weather data is a good tool to analyze a particular segment or location. For future research, more weather data and crash data would be helpful to understand the long term relationships between crashes and weather, as well as relative risk ratios changes. 
Investigating how other factors affects correlate with the relative risk ratios, such as driving speed and traffic volume. Also, impact of rain intensity on crash risk would be evaluated into the performance of the roadway safety measurements. 


\subsection{REFERENCES}

Andrey, Jean, Mills, Brian and Vandermolen, Jessica, (2003). A Temporal Analysis of Weather-Related Collision Risk for Ottawa, Canada: 1990-1998, In TRB 82th Annual Meeting. CD-ROM. Transportation Research Board OF THE National Academies,

Andrey, J. (1989). Relationships Between Weather and Traffic Safety. Ph.D. Dissertation. University of Waterloo, Waterloo, Ontario.

Andrey, J., Suggett, J., Mills, B. and Leahy, M. (2001). Weather-related road accident risks in mid-sized Canadian cities, Canadian Multidisciplinary Road Safety Conference XII Proceedings, London, ON, June page 11-13.

Alfelor, R.M. (2006). Weather-responsive transportation management. In ITE Annual Meeting and Exhibit Compendium of Technical Papers, page 9

Bertness, J. (1980). Rain Related Impacts on Selected Transportation Activities and Utility Services in the Chicago Area. Journal of Applied Meteorology 19:545-556

Berdica, Katja, (2002). An Introduction to Road Vulnerability: What Has Been Done, Is Done and Should Be Done, Transportation Policy, 9, 117-127

Bertini, Robert L. Hansen, Steve, Byrd, Andre and Yin, Thareth (2005), Experience Implementing a User Service for Archived Intelligent Transportation System Data, page 90-99

Codling, P. (1974). Weather and road accidents, In Climatic Resources and Economic Activity, J. Taylor (ed.), page 205-222.

Eisenberg, Daniel (2004). The Mixed Effects of Precipitation on Traffic Crashed, Accident Analysis \& Prevention (36), page 637-647

ElDessouki, M., J. Ivan, A. Sadek, E. Anagnostou, and C. Zhang (2004). Using Relative Risk Analysis to Improve Connecticut Freeway Traffic Safety under Adverse Weather Conditions. Report No. UCNR 14-5. New England (Region One) University Transportation Centers (NEUTC), U.S. Department of Transportation, 
Fatality Analysis Reporting System database: http://wwwfars.nhtsa.dot.gov/Main/index.aspx

Gwynn, David W. (1967). Relationship of Accident Rates and Accident Involvements with Hourly Volumes, Traffic Quarterly, Volume 21, No. 3, page 407-418.

Highway Traffic Safety Administration (NHTSA), Road Weather Management Program: How Do Weather Events Impact Roads? http:/ / ops.fhwa.dot.gov/Weather/q1 roadimpact.htm

Keay, Kevin and Simmons, Ian (2006). Road accidents and rainfall in a large Australian city, Accident Analysis and Prevention (38), page 445-454

Karlaftis, Matthew G.; Golias, Ioannis; (2002). Effects of Road Geometry and Traffic Volumes on Rural Roadway Accident Rates, Accident Analysis and Prevention (34), page 357-365.

Mende, I. (1982). An Analysis of Snowstorm-Related Accidents in Metropolitan Toronto. Master's Thesis, Department of Civil Engineering, University of Toronto, Toronto, Ontario.

National Highway Safety Administration Crash database: http://wwwnrd.nhtsa.dot.gov/departments/nrd30/ncsa/STSI/USA\%20WEB\%20REPORT.HTM

NOAA's Weather and Climate Toolkit

Sherretz, L. and Farhar, B. (1978). An Analysis of the Relationship Between Rainfall and the Occurrence of Traffic Accidents. Journal of Applied Meteorology (17) page 711-715.

Smith, K. (1982). How Seasonal and Weather Conditions Influence Road Accidents in Glasgow. Scottish Geographical Magazine (98), page 103-114.

Sun, Xiaoduan, Hu, Han, Habib, Emad and Magri, Daniel (2010). Quantifying Crash Risk under Inclement Weather with Radar Rainfall Data and Matched-Pair Method, In TRB 89th Annual Meeting. CD-ROM. Transportation Research Board OF THE National Academies 
Suggett, J; (1999). The Effect of Precipitation on Traffic Safety in the City of Regina. Master of Science thesis, University of Regina, Saskatoon

Verwey, Willem B.; Zaidel, David M.; (2000). Predicting Drowsiness Accidents from Personal Attributes Eye Blinks and Ongoing Driving Behavior, Personality and Individual Differences(28), page 123-142.

Walter, Martha L. et al; (2003). A Journalist's Handbook on Environmental Risk Assessment, Produced by Foundation for American Communications and National Sea Grant College Program, see http: / / ruby.fgcu.edu/Courses/Twimberley/IDS3920/main.html

Weather Station: http:/ / en.wikipedia.org/wiki/Weather_station Weather radar: http:// en.wikipedia.org/wiki/Weather radar 
APPENDIX A: Summary of studies

\begin{tabular}{|c|c|c|c|}
\hline $\begin{array}{l}\text { Authors } \\
\text { (year) }\end{array}$ & Sample & Methods & Key Finds \\
\hline $\begin{array}{l}\text { Andrey } \\
\text { (2003) }\end{array}$ & $\begin{array}{l}\text { Ottawa, 1990- } \\
1998\end{array}$ & $\begin{array}{l}\text { Compare risk of } \\
\text { collision and injury } \\
\text { during precipitation } \\
\text { relative to normal } \\
\text { seasonal }\end{array}$ & $\begin{array}{l}\text { - Collision risk } \\
\text { increasing more } \\
\text { than } 100 \% \text { for rain } \\
\text { - } 50 \% \text { in winter }\end{array}$ \\
\hline $\begin{array}{l}\text { Edwards } \\
\text { (1998) }\end{array}$ & $\begin{array}{l}\text { England and } \\
\text { Wales, } \\
\text { 1980-1990 }\end{array}$ & $\begin{array}{l}\text { Compare severity mix } \\
\text { of crashes during rain } \\
\text { to } \\
\text { severity mix during dry } \\
\text { weather (weather } \\
\text { conditions per police } \\
\text { reports for crashes) }\end{array}$ & $\begin{array}{l}\text { For rainy weather, } \\
\text { the fatal: injury- } \\
\text { only :non-injury } \\
\text { crash ratio is } \\
\text { 18:227:755 } \\
\text { For dry weather, } \\
\text { the ratio is } \\
\text { 21:235:744 }\end{array}$ \\
\hline $\begin{array}{l}\text { Andrey } \\
\text { and } \\
\text { Yagar } \\
(1993)\end{array}$ & $\begin{array}{l}\text { Calgary and } \\
\text { Edmonton, } \\
\text { 1979-1983 }\end{array}$ & $\begin{array}{l}\text { Matched-pair approach: } \\
\text { compare "rain events" } \\
\text { to } \\
\text { comparable time } \\
\text { periods without rain on } \\
\text { different } \\
\text { week }\end{array}$ & 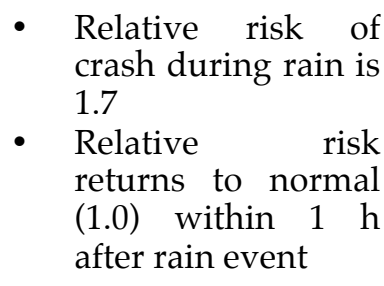 \\
\hline $\begin{array}{l}\text { Sun } \\
(2009)\end{array}$ & $\begin{array}{l}\text { Louisiana, } \\
\text { 2002-2006, } \\
\text { Radar weather } \\
\text { data, } \\
\text { Radar Pixels } \\
\text { Selections }\end{array}$ & $\begin{array}{l}\text { Matched-Pair Methods: } \\
\text { Comparing rain events } \\
\text { to comparable time } \\
\text { period without rain on } \\
\text { different week, }\end{array}$ & $\begin{array}{l}\text { - On average } \\
\text { relative risk ratio } \\
\text { are greater than 1; } \\
\text { More than } 50 \% \text { of } \\
\text { all urban traffic } \\
\text { crashes at } \\
\text { intersections } \\
\text { Run-off-roadway is } \\
\text { common crashes in } \\
\text { rainy days, } 4 \text { times } \\
\text { on urban freeway, } \\
\text { twice on rural } \\
\text { freeway }\end{array}$ \\
\hline
\end{tabular}


APPENDIX B: NEXRAD Ten-minute Precipitation by Month
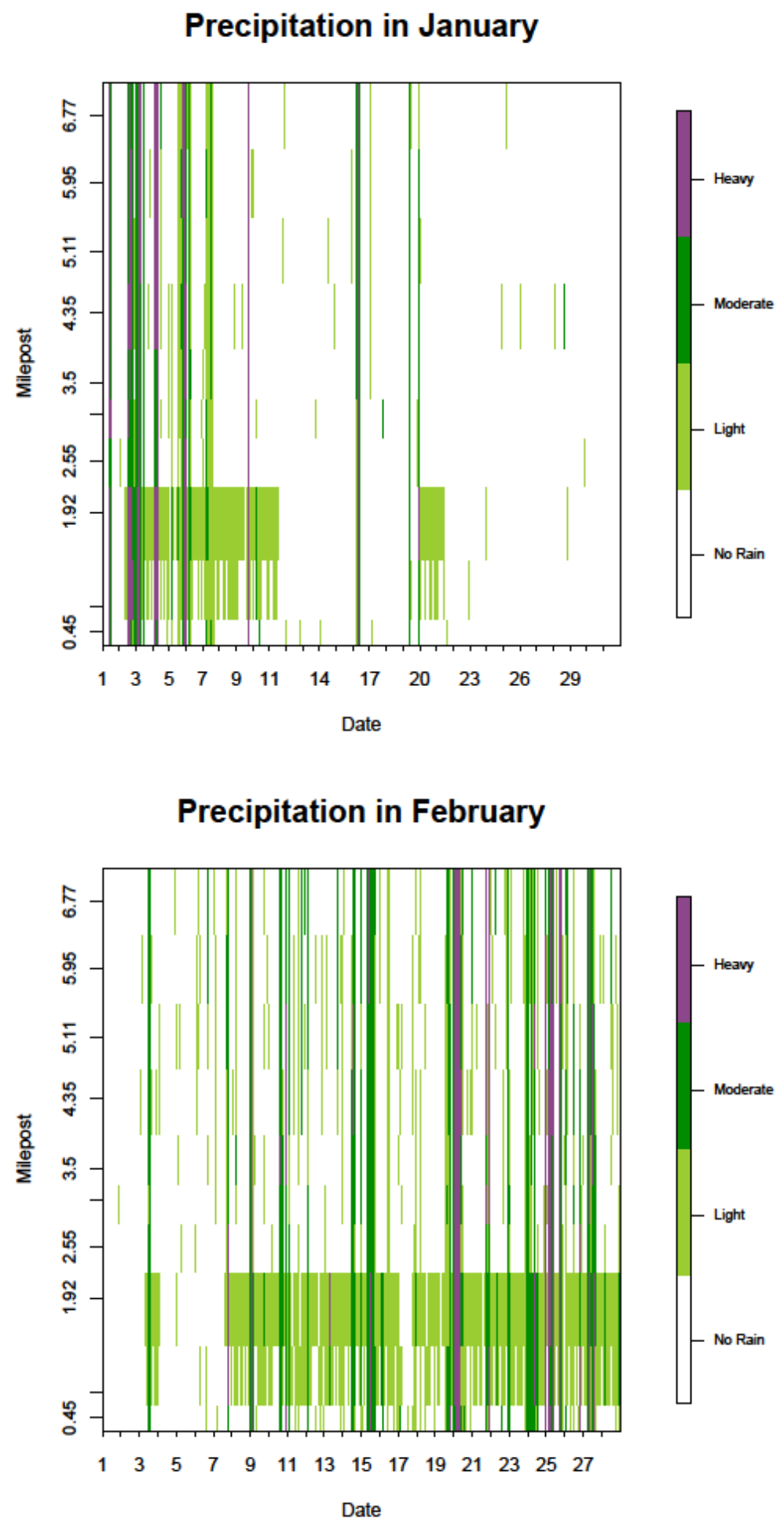
Precipitation in March

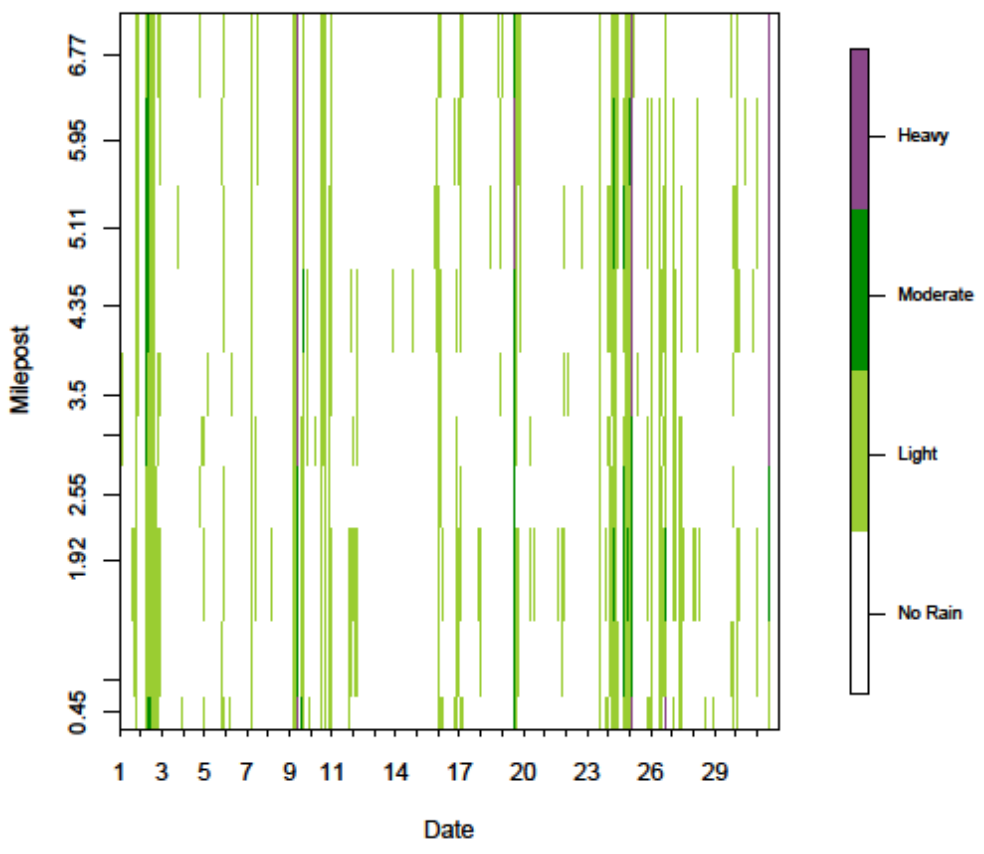

Precipitation in April

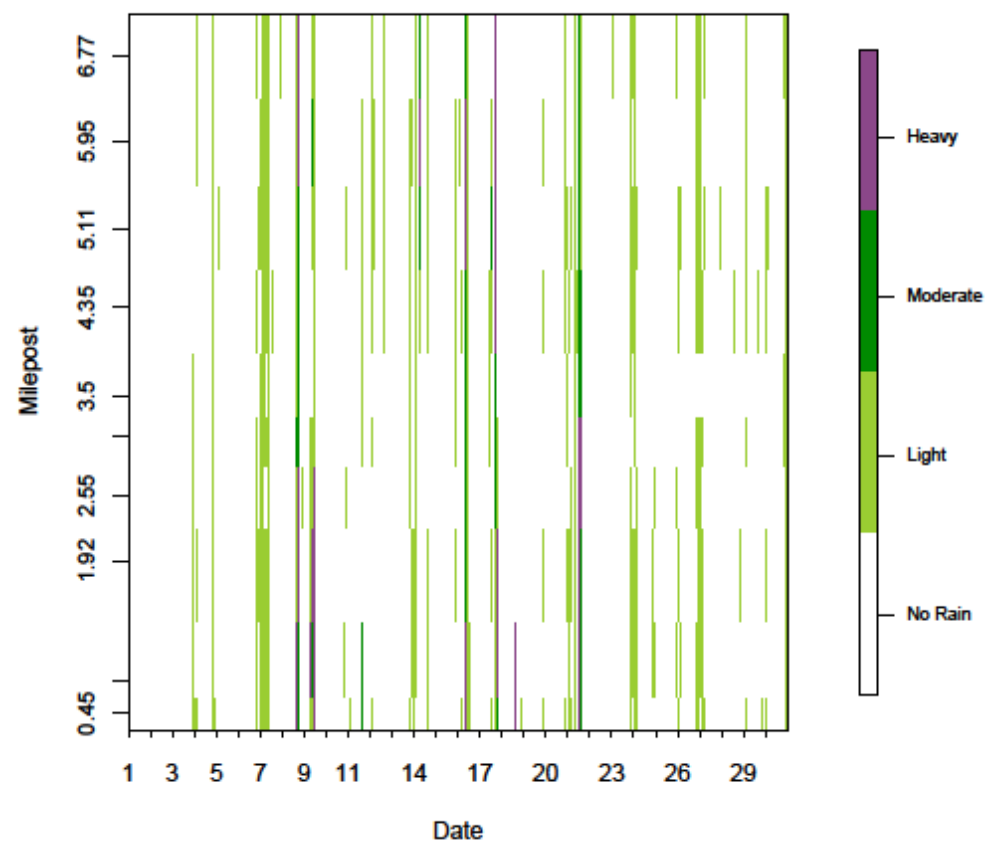


Precipitation in May

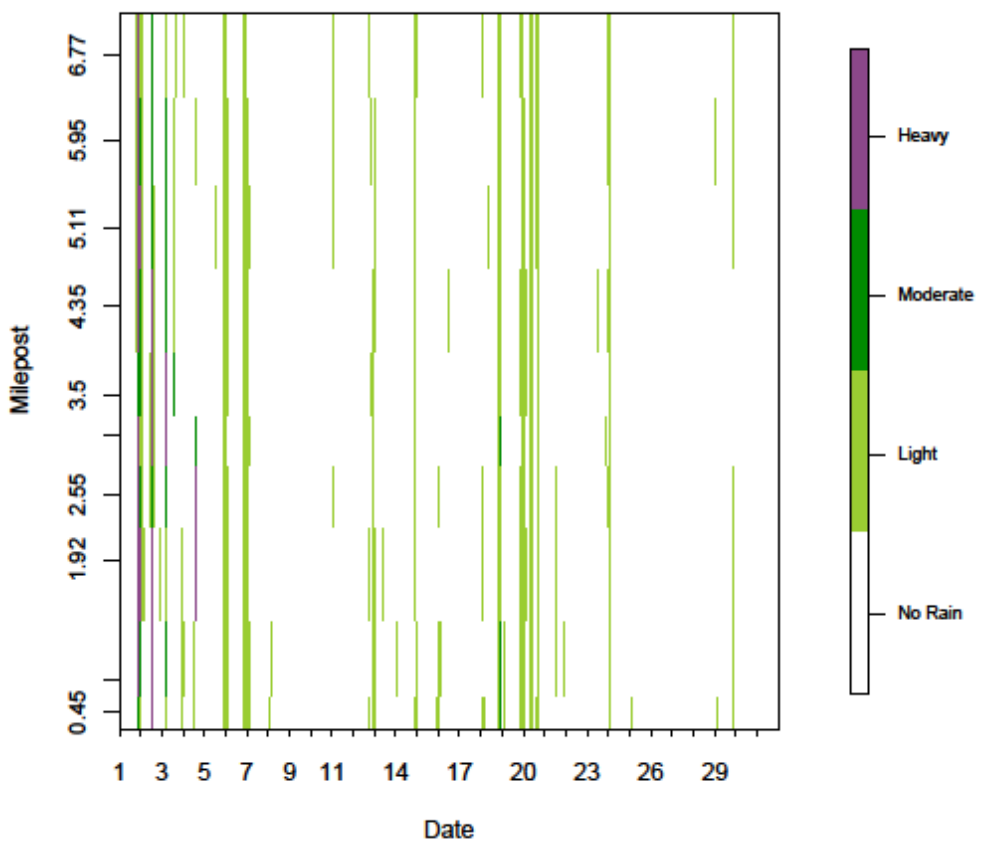

Precipitation in June

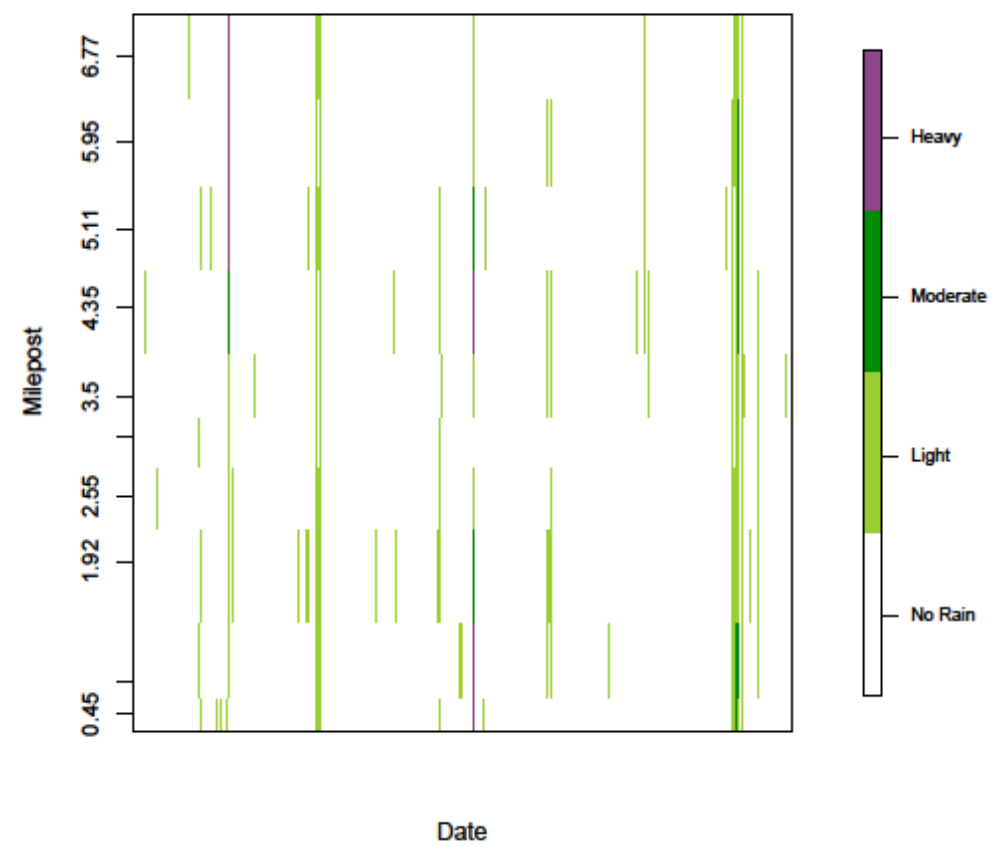



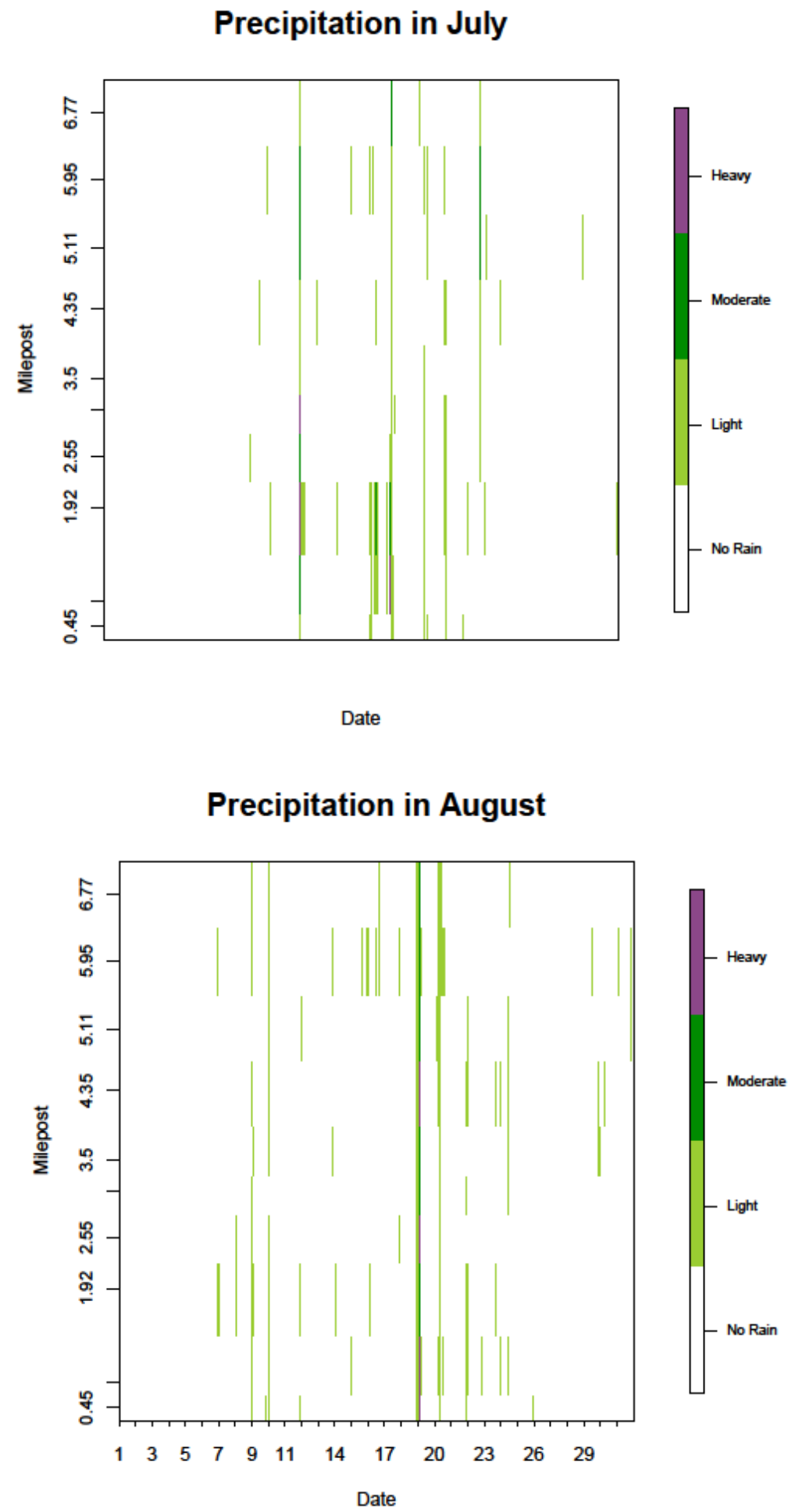

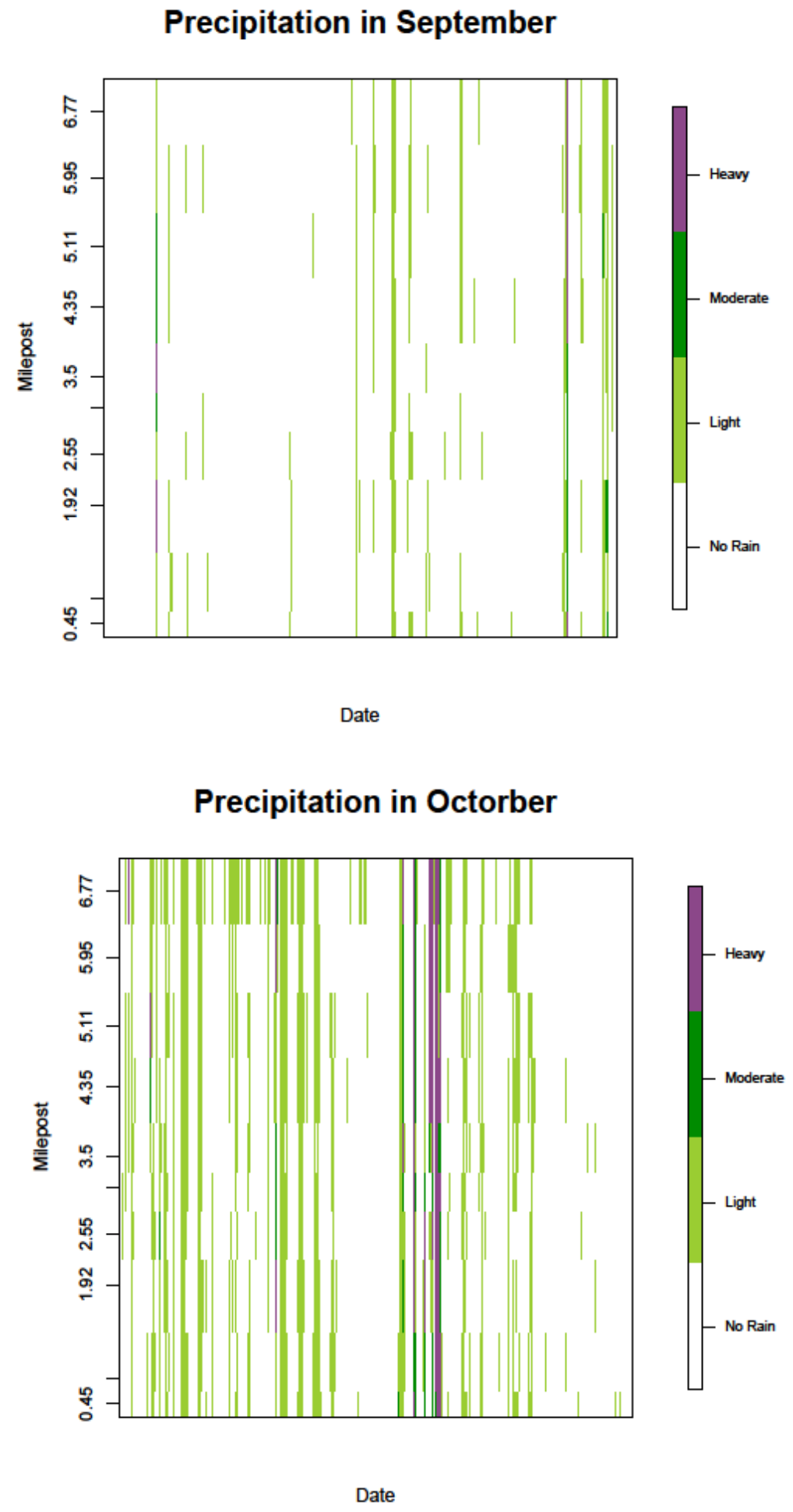


\section{Precipitation in November}

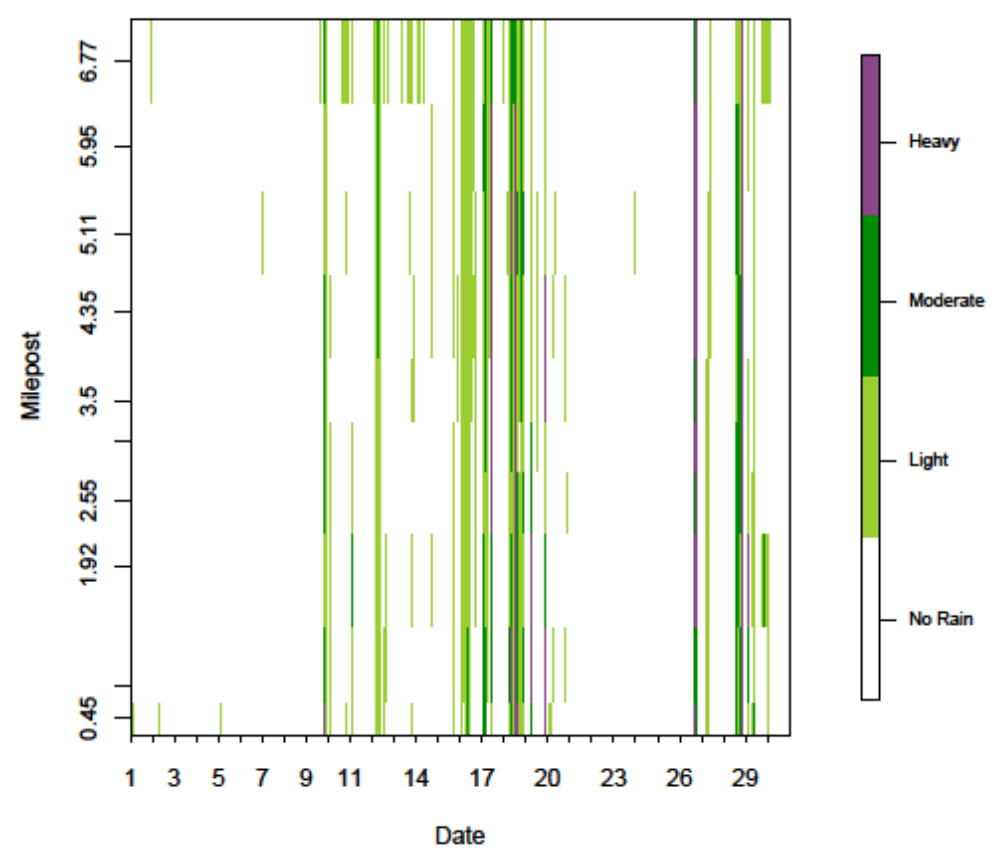

Precipitation in December

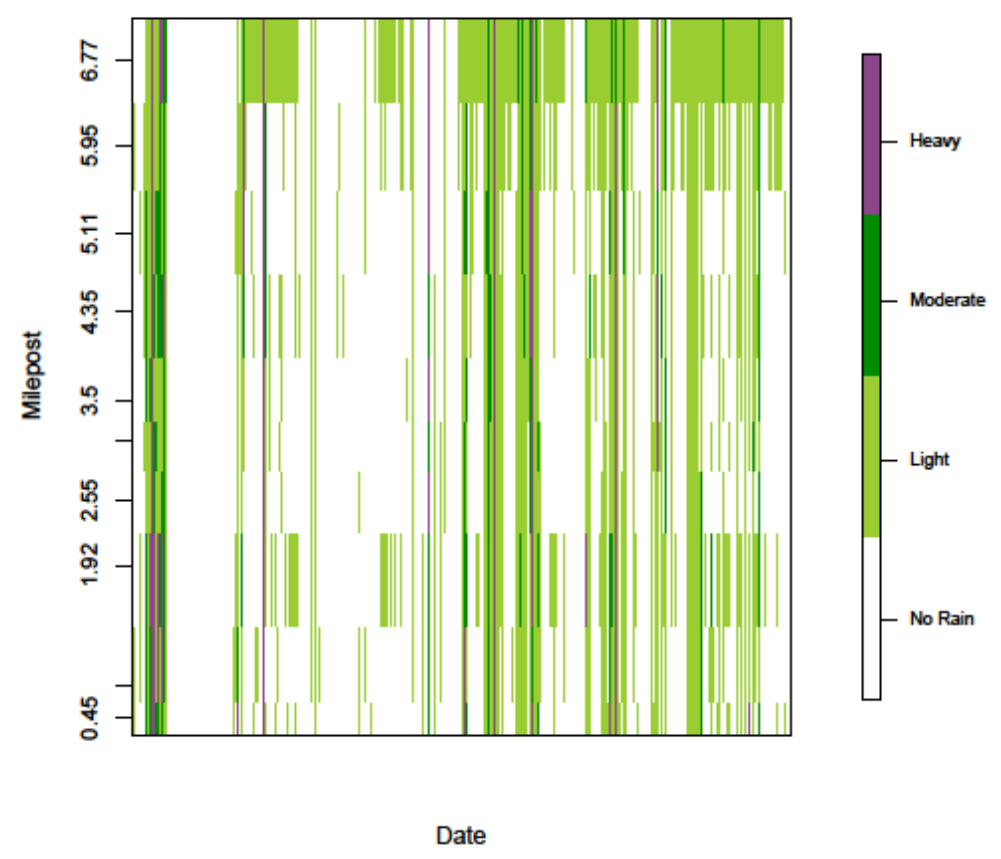



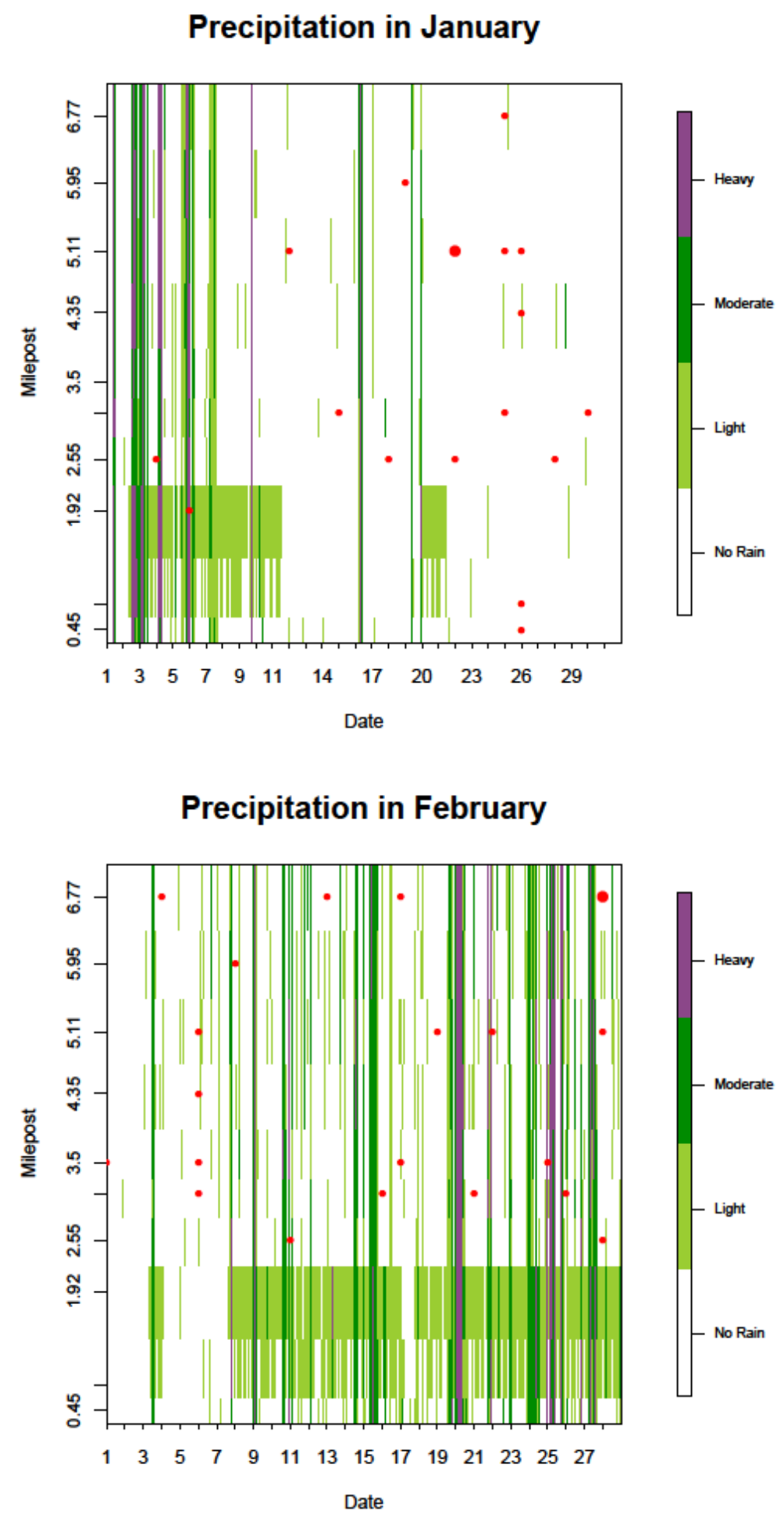
Precipitation in March

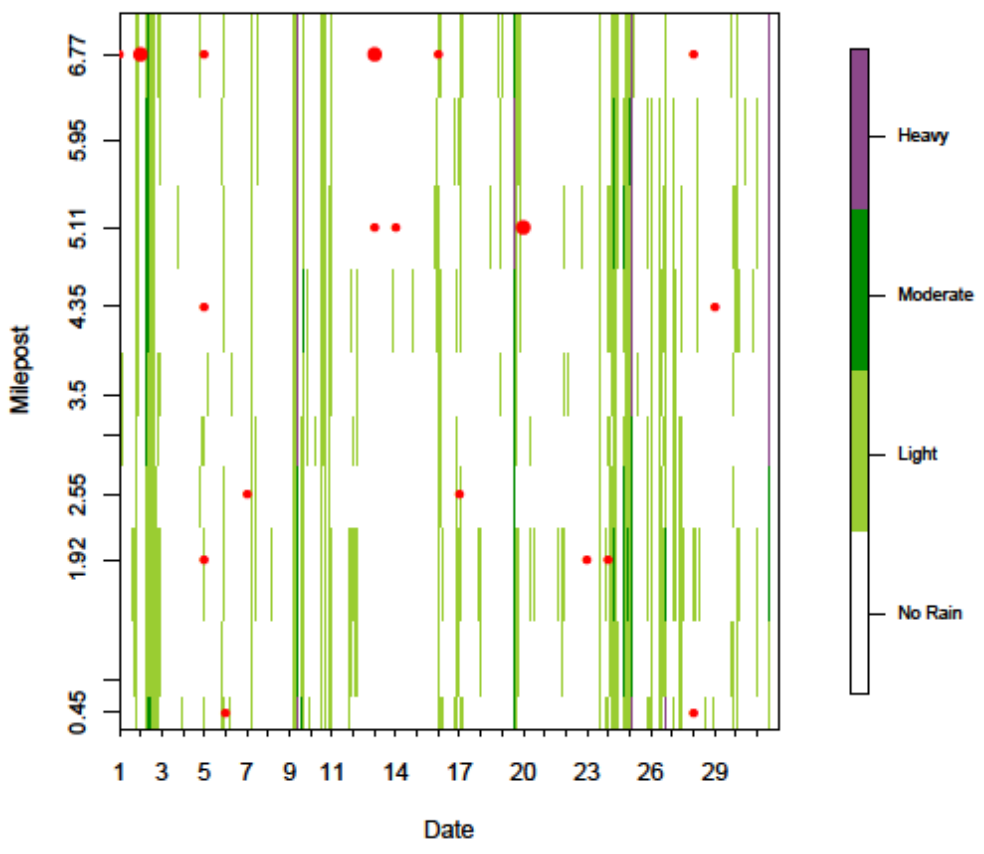

Precipitation in April

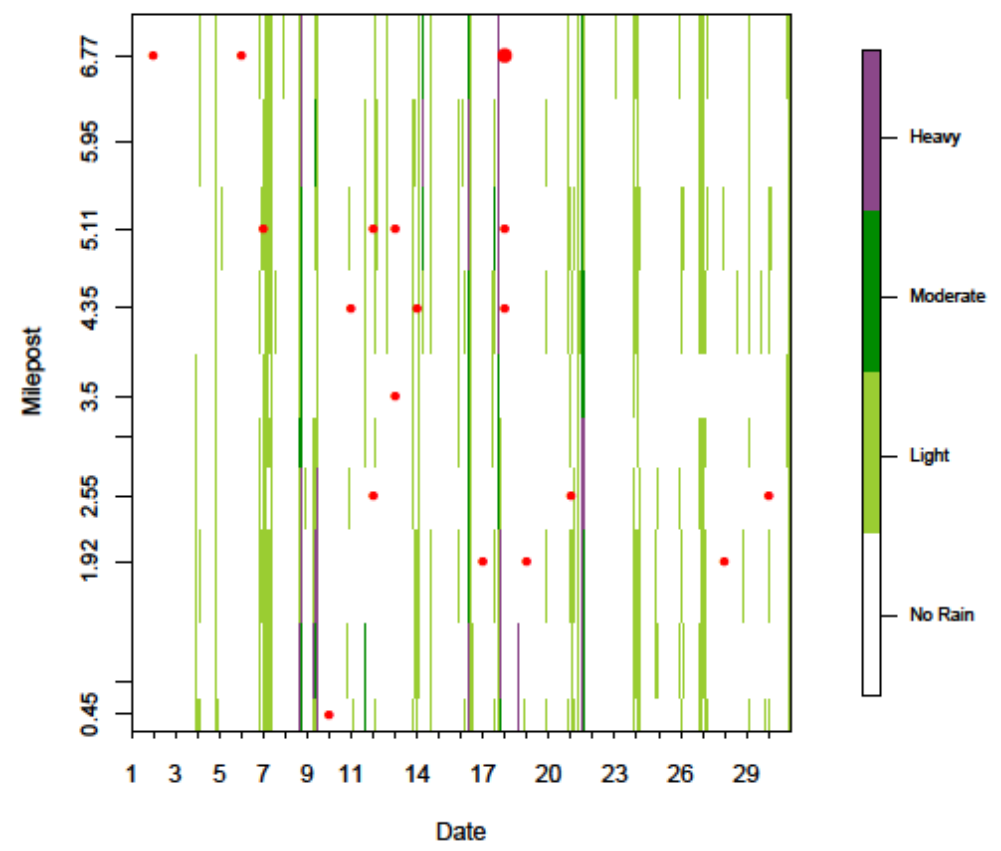


Precipitation in May

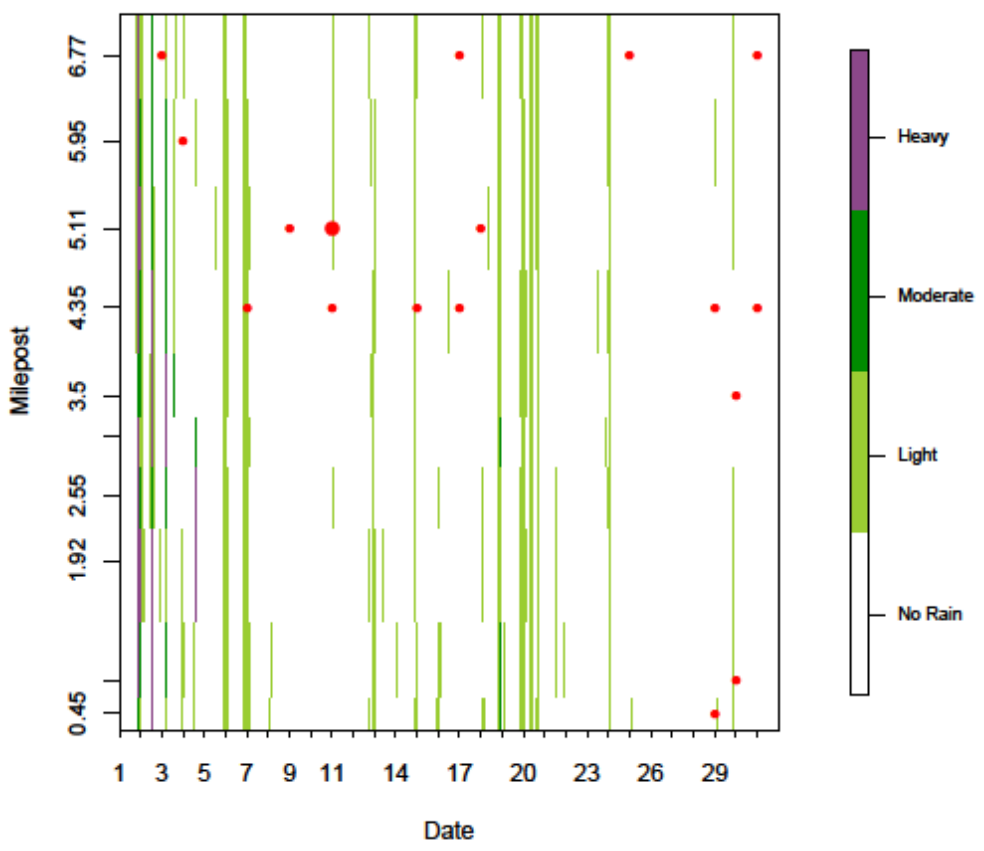

Precipitation in June

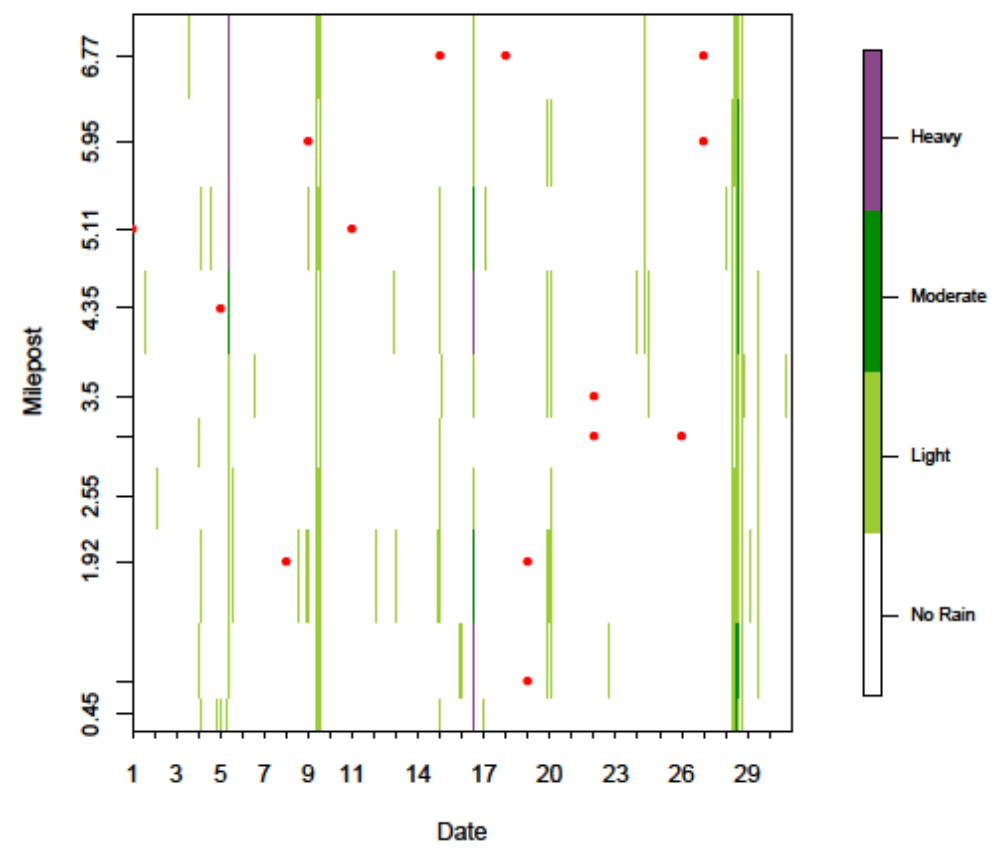




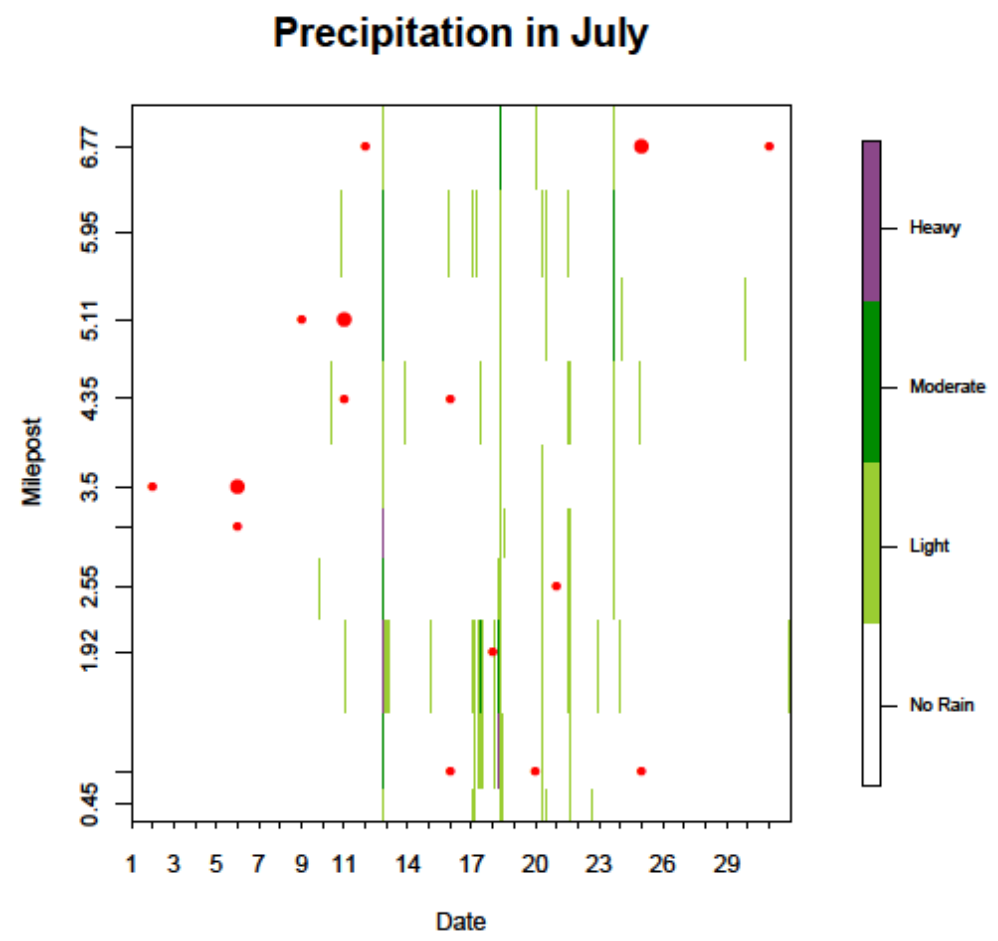

Precipitation in August

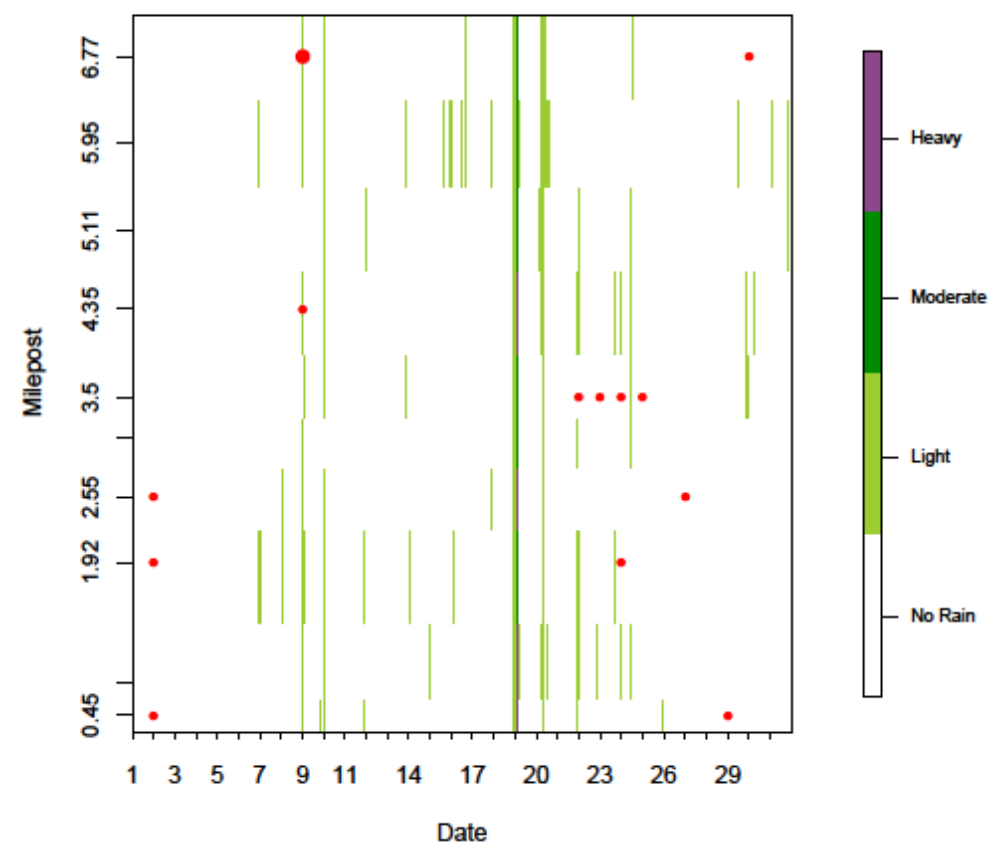


Precipitation in September

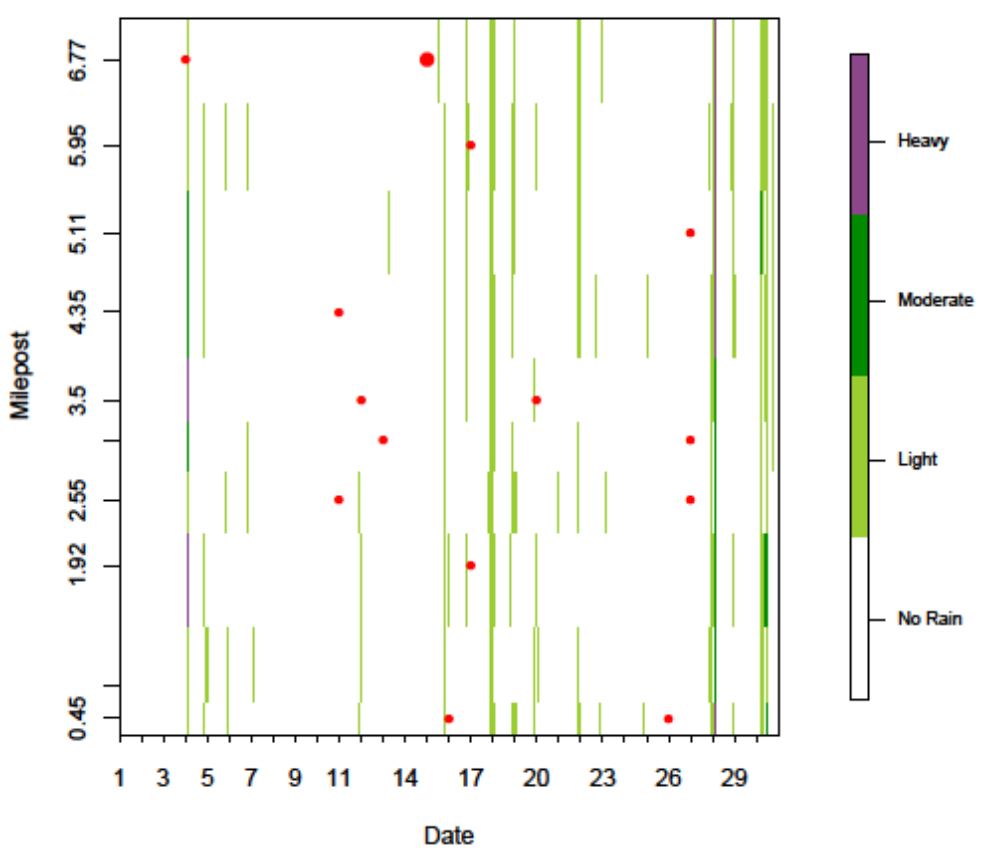

Precipitation in Octorber

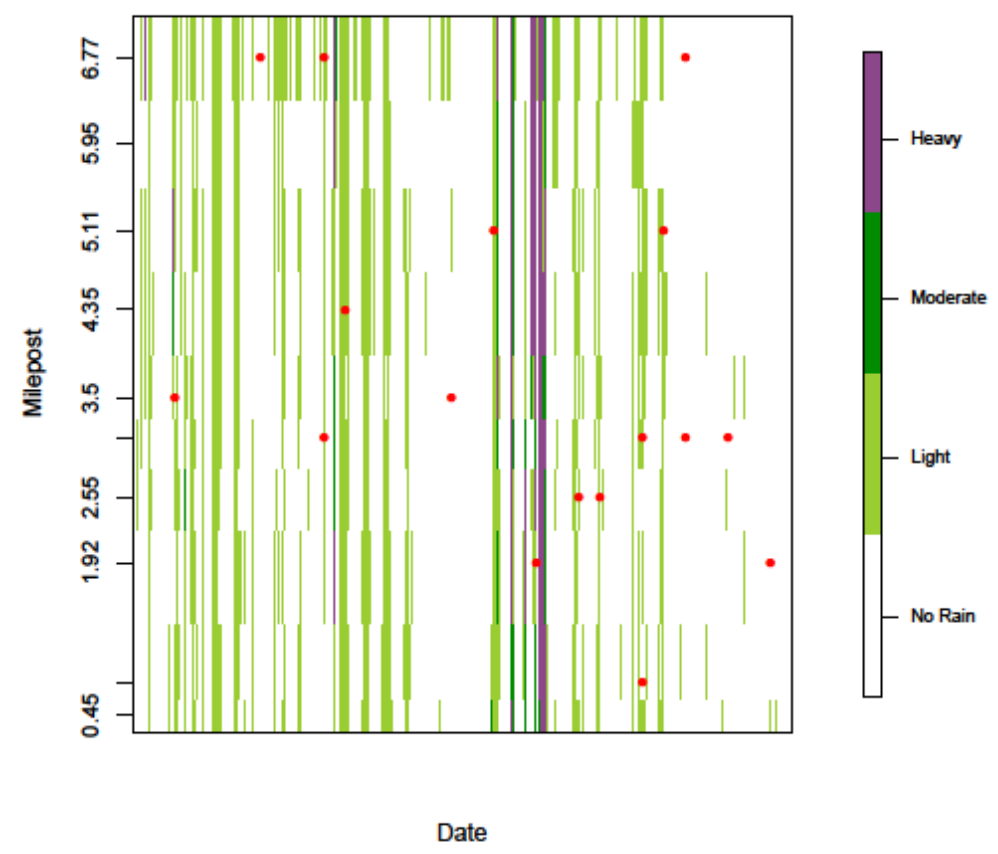


Precipitation in November

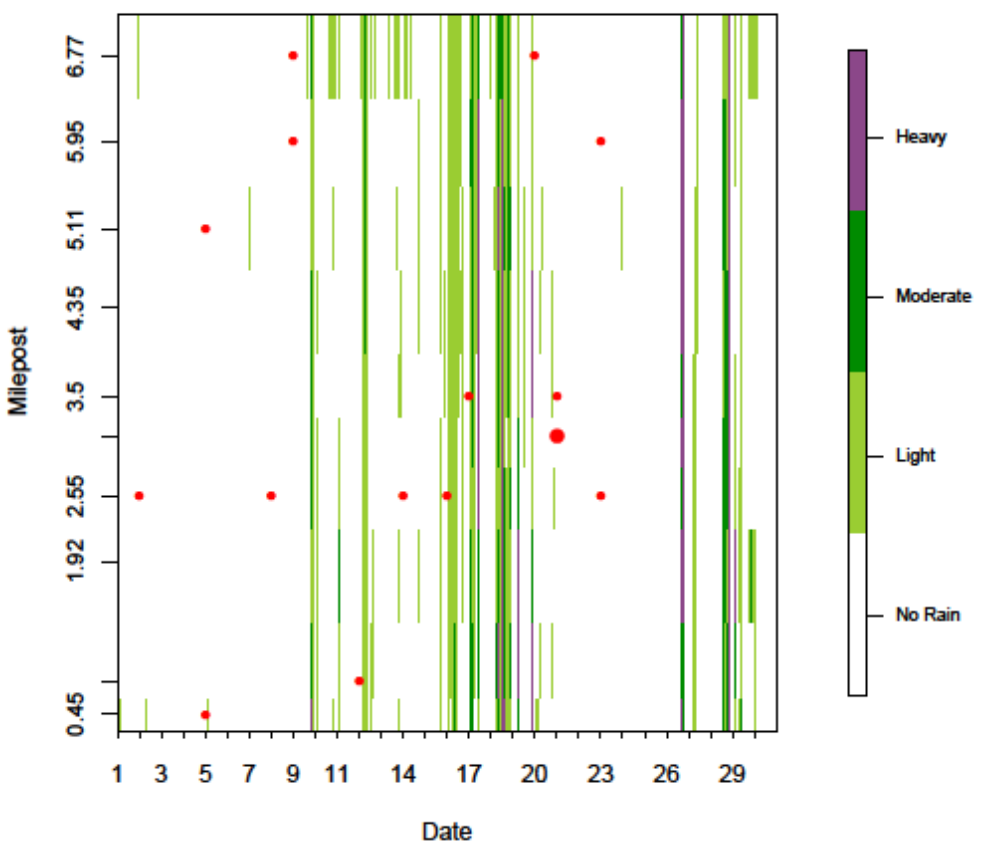

Precipitation in December

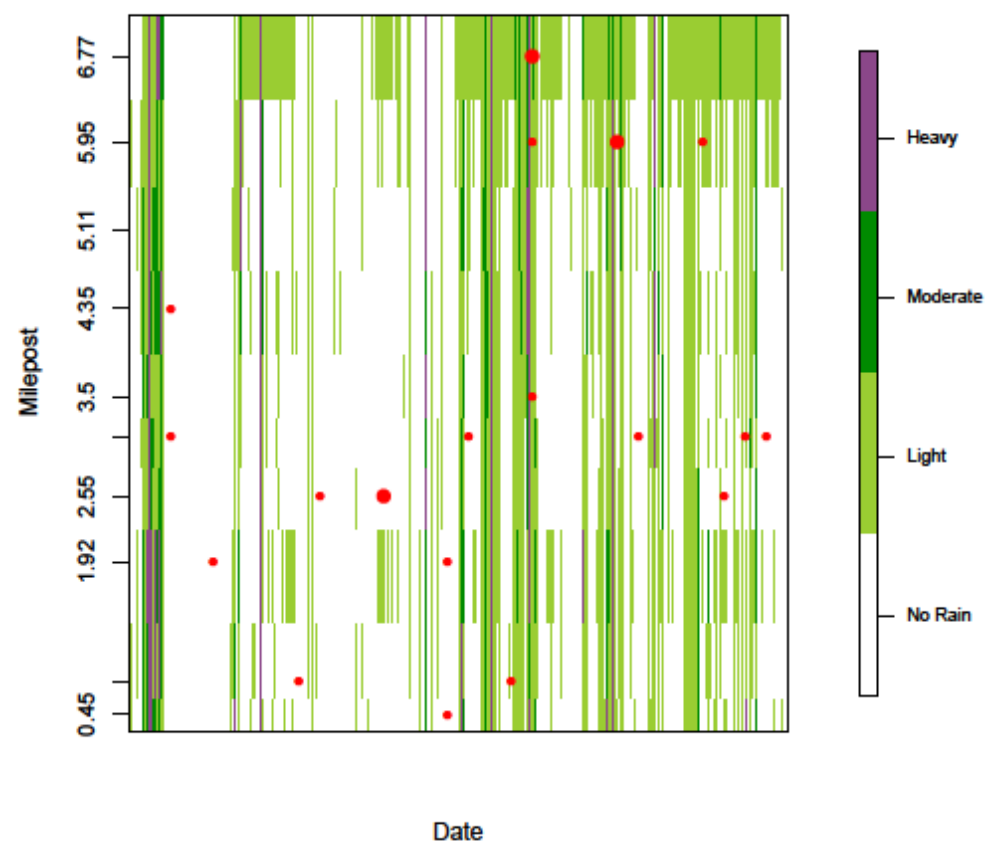


APPENDIX D: PORTAL Hourly Precipitation by Month
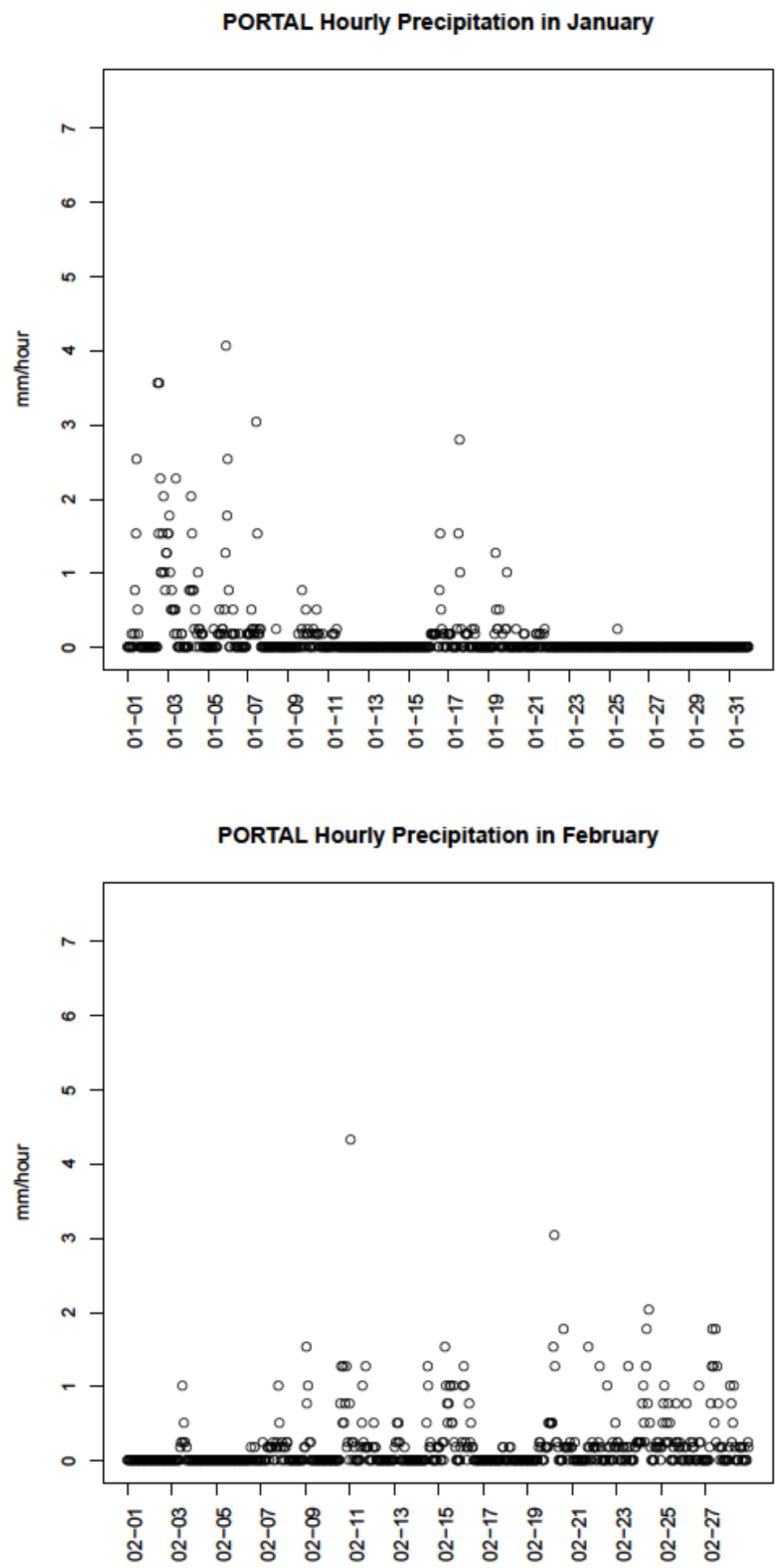

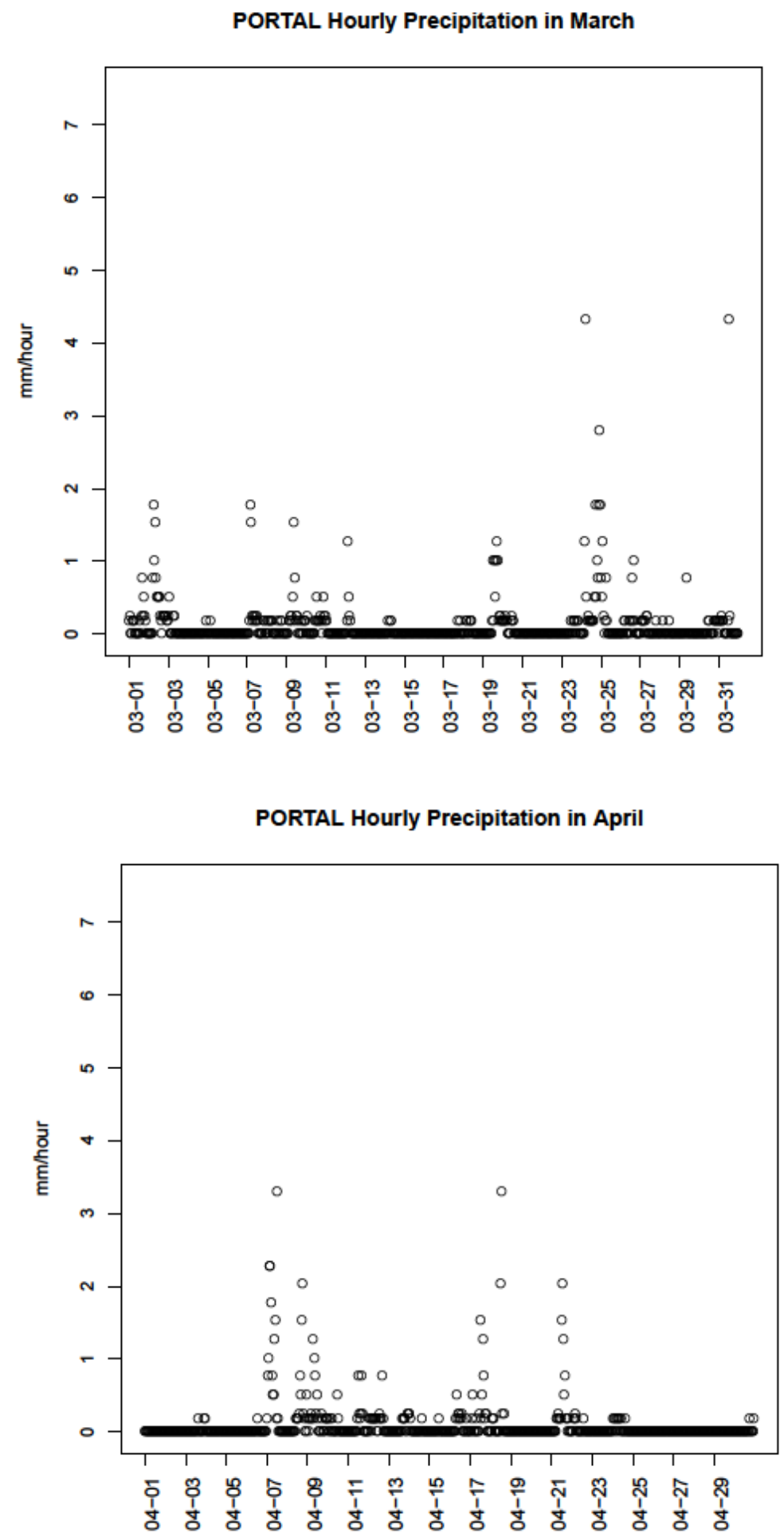

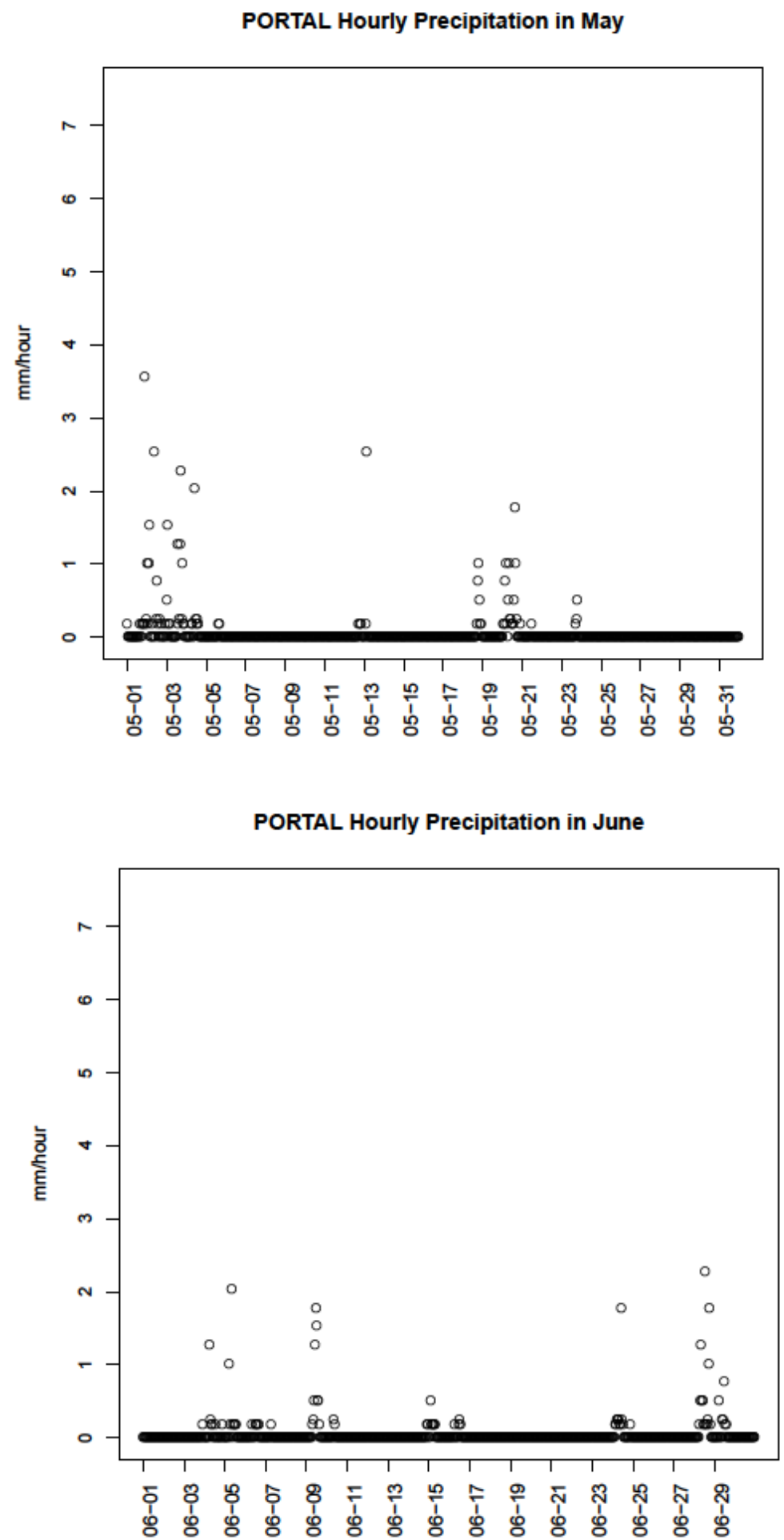

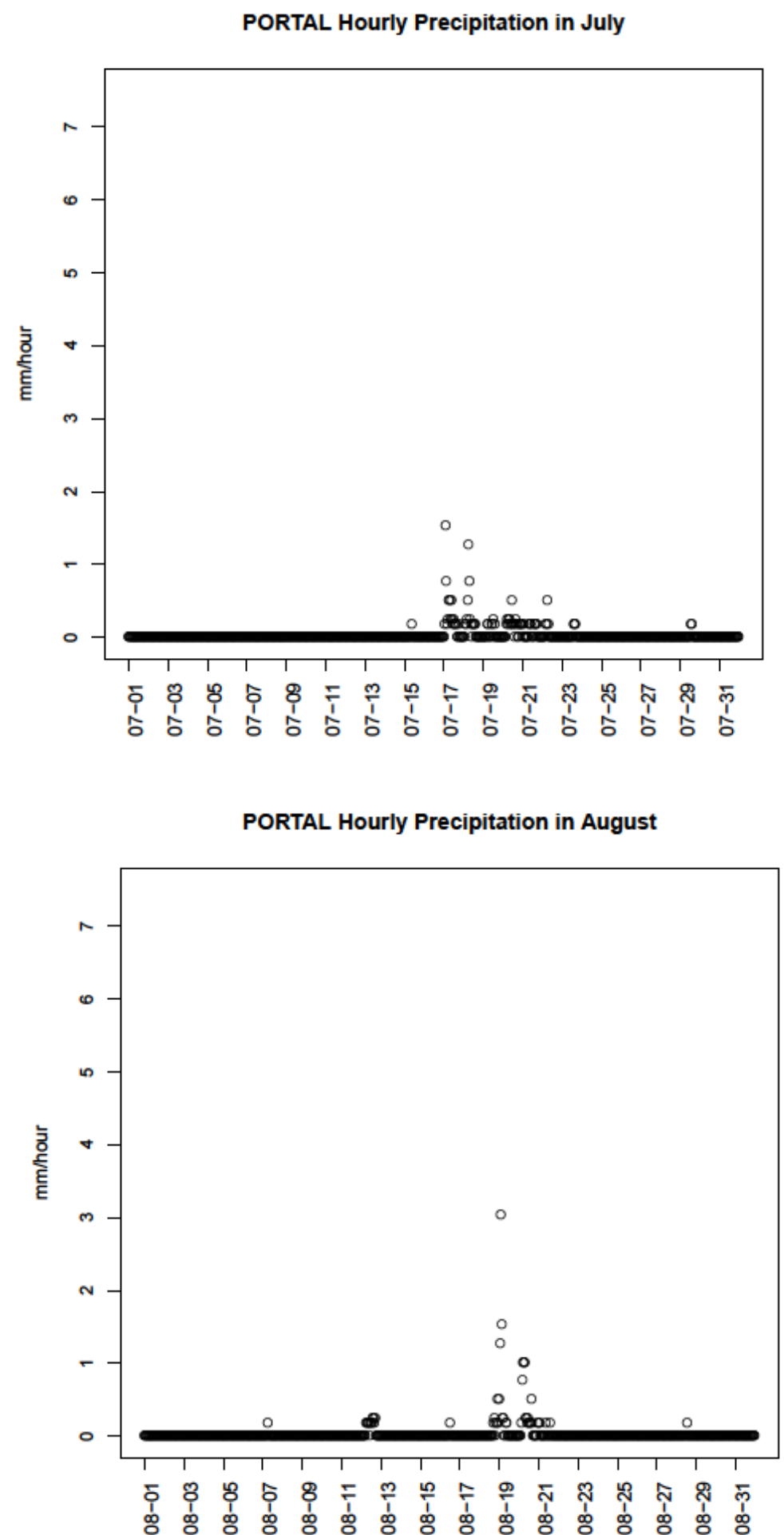

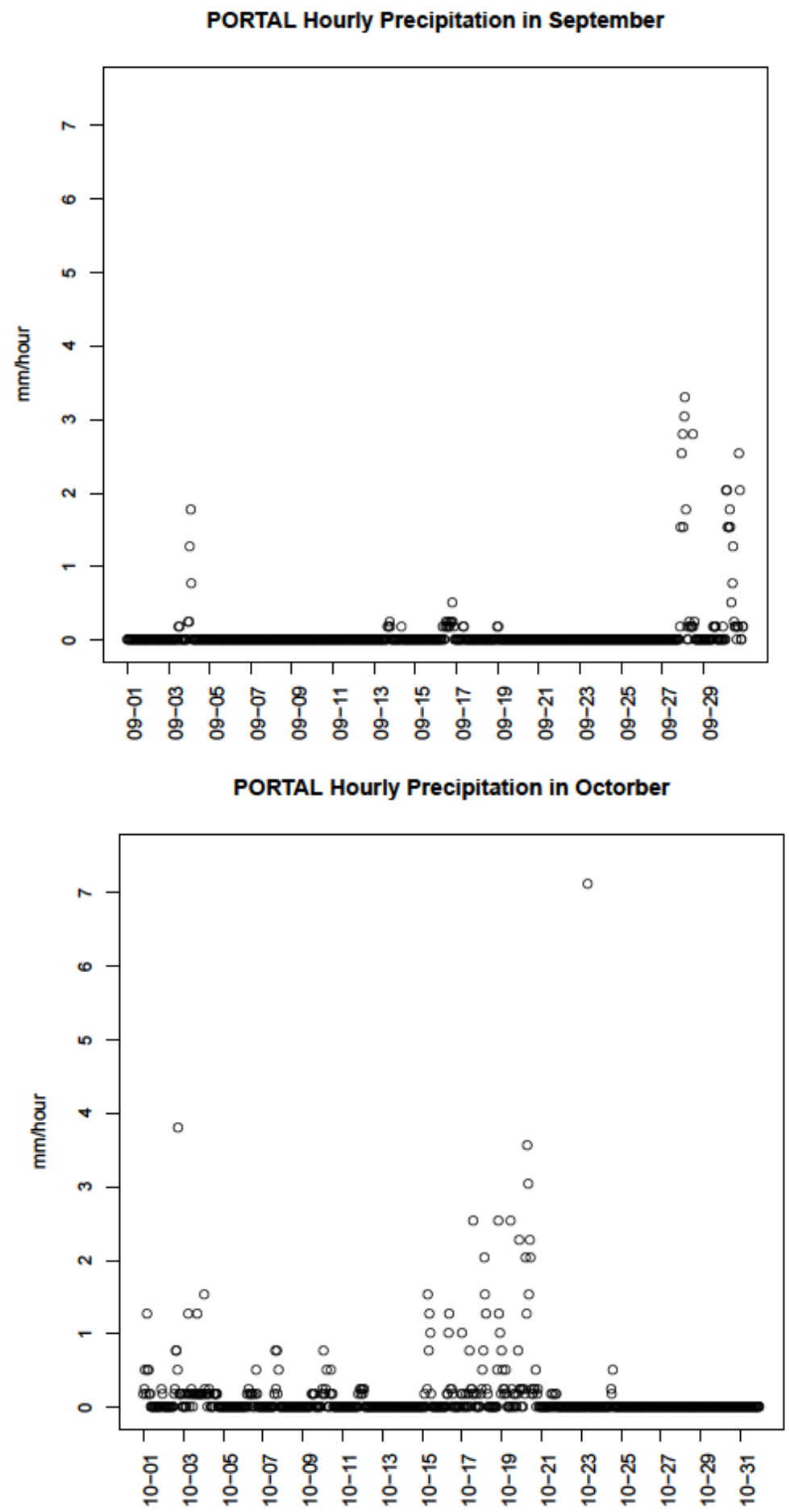

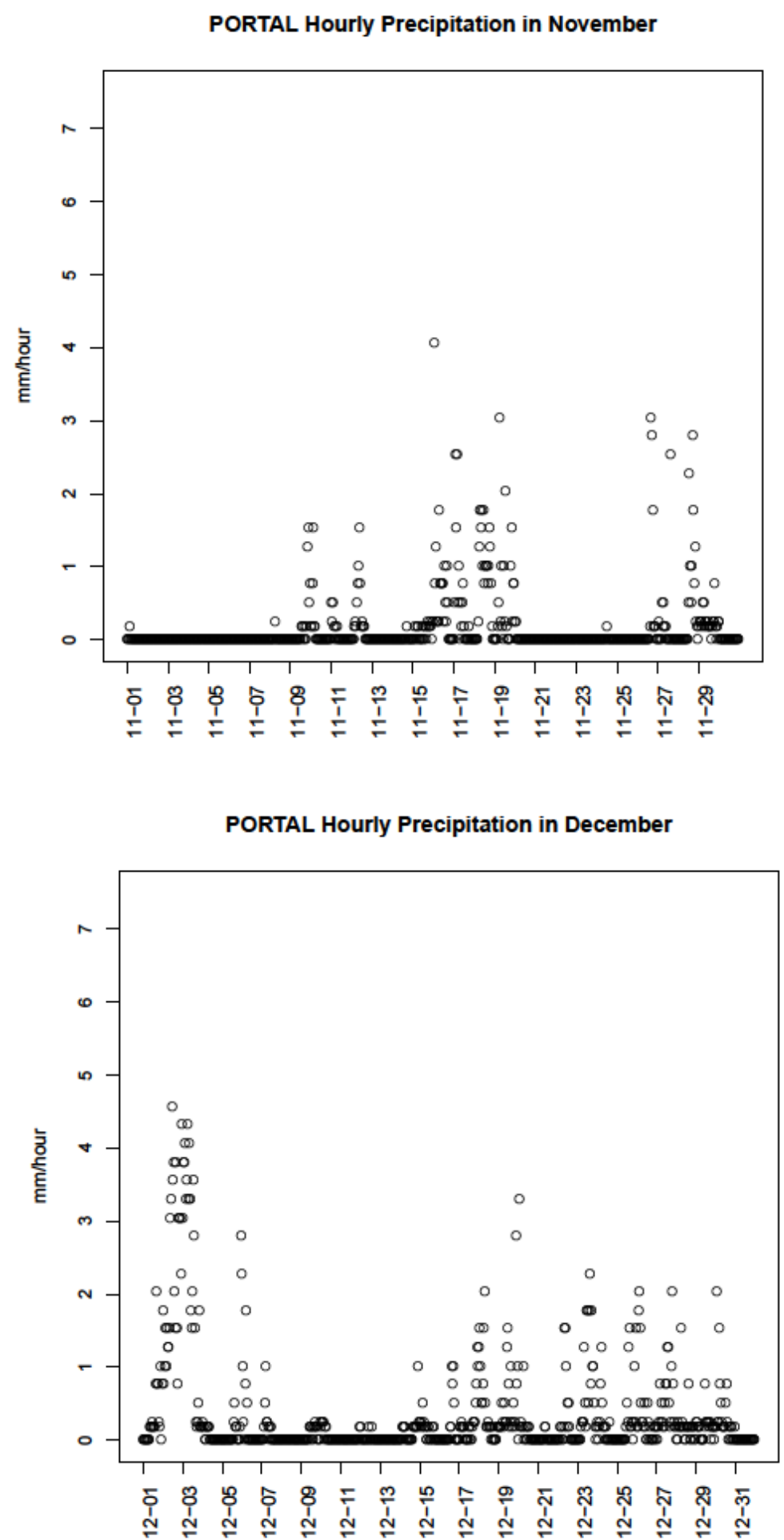